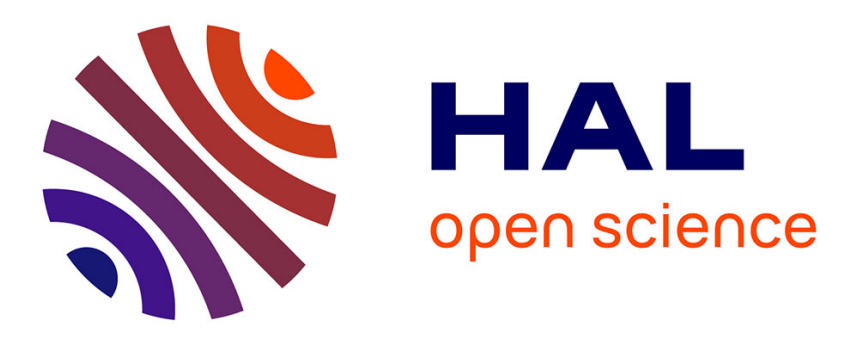

\title{
The effect of quenching and defects size on the HCF behaviour of Boron steel
}

Etienne Pessard, Benjamin Abrivard, Franck Morel, Foued Abroug, Philippe Delhaye

\section{To cite this version:}

Etienne Pessard, Benjamin Abrivard, Franck Morel, Foued Abroug, Philippe Delhaye. The effect of quenching and defects size on the HCF behaviour of Boron steel. International Journal of Fatigue, 2014, 68, pp.80-89. 10.1016/j.ijfatigue.2014.06.002 . hal-01061163

\section{HAL Id: hal-01061163 https://hal.science/hal-01061163}

Submitted on 5 Sep 2014

HAL is a multi-disciplinary open access archive for the deposit and dissemination of scientific research documents, whether they are published or not. The documents may come from teaching and research institutions in France or abroad, or from public or private research centers.
L'archive ouverte pluridisciplinaire HAL, est destinée au dépôt et à la diffusion de documents scientifiques de niveau recherche, publiés ou non, émanant des établissements d'enseignement et de recherche français ou étrangers, des laboratoires publics ou privés. 


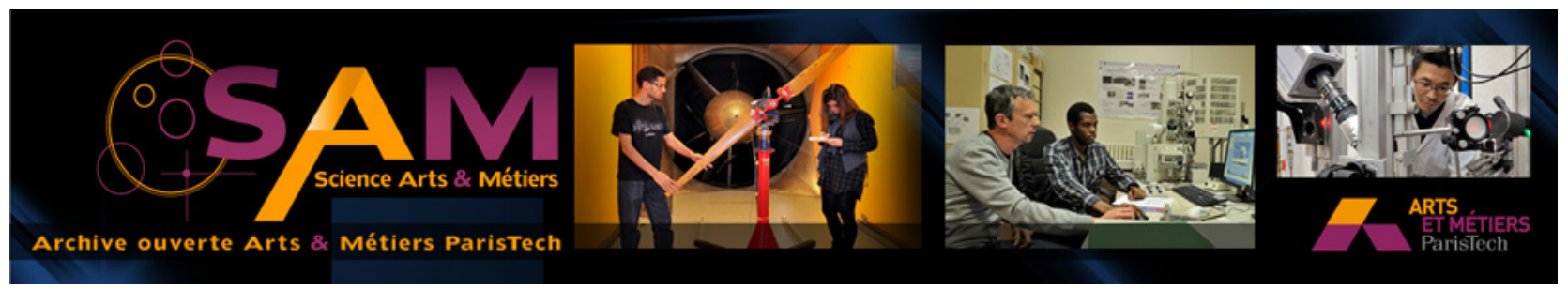

Science Arts \& Métiers (SAM)

is an open access repository that collects the work of Arts et Métiers ParisTech researchers and makes it freely available over the web where possible.

This is an author-deposited version published in: http://sam.ensam.eu

Handle ID: .http://hdl.handle.net/10985/8460

\section{To cite this version :}

Etienne PESSARD, Benjamin ABRIVARD, Franck MOREL, Foued ABROUG, Philippe DELHAYE - The effect of quenching and defects size on the HCF behaviour of Boron steel - International Journal of Fatigue - Vol. 68, p.80-89 - 2014 


\title{
The effect of quenching and defects size on the HCF behaviour of Boron steel
}

\author{
Etienne Pessard $^{\mathrm{a}}$, Benjamin Abrivard ${ }^{\mathrm{a}, \mathrm{b}}$, Franck Morel $^{\mathrm{a}}$, Foued Abroug ${ }^{\mathrm{a}}$, Philippe Delhaye ${ }^{\mathrm{b}}$ \\ ${ }^{a}$ LAMPA, Arts et Métiers ParisTech Angers, 2 Bd du Ronceray, 49035 Angers, France \\ ${ }^{b}$ Renault SAS, Le Mans 72086, France
}

\begin{abstract}
This work investigates the effect of natural and artificial surface defects and quenching on the fatigue strength of a Boron Steel (22MnB5). A vast experimental campaign has been undertaken to study the high cycle fatigue behaviour and more specifically the fatigue damage mechanisms observed in quenched and untreated materials, under different loading conditions and with differents artificial defects sizes (from $25 \mu \mathrm{m}$ to $370 \mu \mathrm{m}$ radius). In order to test the sheet metal in shear an original test apparatus is used. The critical defect size is determined to be $100 \pm 50 \mu m$. This critical size does not appear to depend on the loading type or the microstructure of the material (i.e. ferritic-perlitic or martensitic). However, for large defects, the quenched material is more sensitive to the defect size than the untreated material. For a defect size range of $100 \mu \mathrm{m}$ to $300 \mu \mathrm{m}$ the slope of the Kitagawa-Takahashi diagram is approximately $-1 / 3$ and $-1 / 6$ for the quenched and untreated materials respectively. A probabilistic approach that leads naturally to a probabilistic Kitagawa type diagram is developed. This methodology can be used to explain the relationship between the influence of the heat treatment and the defect size on the fatigue behaviour of this steel.
\end{abstract}

Keywords: Probabilistic Kitagawa-Takahashi diagram, Fatigue damage mechanisms, High cycle fatigue, Boron Steel, Artificial defects

\footnotetext{
*Corresponding author. Tel.: +332412073 79; fax: +33241207320.

Email address: etienne.pessard@angers.ensam.fr()
} 


\section{Introduction}

The 22MnB5 steel, commercially referred to as Usibor 1500 by Arcelor Mittal, has been developed with the aim of reducing the mass of structural components used in the automotive industry. This material is obtained by hot rolling.A small addition of Boron has almost no effect on the fatigue limit of the non-heat treated material [1] but significantly increases the quenchability or hardenability of the material.

The Hot Forming Die Quenching process (HFDQ), in which the sheet metal is austenized and subsequently stamped in a cooled die, is an interesting from an industrial and economic point of view because the sheet forming process and heat treatment are combined in one step [2]. However, for the HFDQ process to be viable, a material with good quenchability or hardenability must be used. Boron steels are an ideal candidate for this process and much research has been devoted to the characterization of the thermo-mechanical behaviour of these steels [3, 4].

Considerable progress has been made concerning the HFDQ process and it is now possible to vary the final microstructure of a component by optimizing the way in which the tooling is cooled. Some structural components, such as automotive B-pillars, may benefit from regions that have a lower strength and greater ductility for improved crash performance [5].

Another method of obtaining a heterogeneous microstructure is to manufacture the product by conventional sheet metal forming processes and then to locally quench zones of the component by induction heating. The rear axle beam used in Renault vehicles is a good example of the usefulness of this method. As the axle beam is principally subject to combined tension-torsion loads, highly loaded zones can be identified (see Figure 1). It is therefore, a priori, not necessary to fully heat treat the entire component as a local heat treatment in certain zones could significantly reduce the manufacturing time.

Even though there have been recent advances concerning the processes used to generate components with microstructural gradients, little research has focused on fatigue criteria that are capable of explicitly incorporating the effect of the microstructure. Also, little work has been conducted on the effect of the heat treatment on the fatigue behaviour of Boron steels. The work of Geary and King [6] can be noted as an exception. His work is focused on the effect of the heat treatment and 
in particular the austenitization temperature and the cooling rate on the crack propagation threshold. Concerning the effect of quenching by induction, the majority of research has been focused on massive parts or on the treated surface [7, 8, 9].

The results of an experimental campaign to characterize the fatigue behaviour of heat treated and untreated 22MnB5 steel containing different sized artificial defects under different cyclic stress states are presented. This work focuses on small artificial and natural defects which are similar to those that can be observed in real components such as surface scratches or non-metallic inclusions. Hence, the long crack domain or the Kitagawa diagram is not explicitly investigated in the experimental work. After an analysis of the damage mechanisms, a probabilistic approach to take into account the combined effect of the defects and the heat treatment on the fatigue behaviour is developed.

\section{Material and experimental procedure}

\subsection{The material}

The material studied in this work is a ferrite-pearlite $22 \mathrm{MnB} 5$ steel commercially referred to as Usibor 1500. Its chemical composition is given in Table1. The material was produced in the form of rolled sheets and contain non-metallic inclusions $\left(\mathrm{Al}_{2} \mathrm{O}_{3}\right)$. The maximum diameter of these inclusions, observed on the failure surface of fatigue specimens, was approximately $45 \mu \mathrm{m}$.

The material is isotropic in terms of its mechanical behaviour and its mechanical properties are presented in Table 2. The heat treatment consists of an austenitization at $950^{\circ} \mathrm{C}$ for 6 minutes, followed by an oil quench at room temperature. Observations using a Scanning Electron Microscope (SEM) showed that the material has a ferritic-pearlitic microstructure in its initial or untreated state with an average grain size of $5 \mu \mathrm{m}$ and a martensitic microstructure after the heat treatment (see Fig. 2).

\subsection{Fatigue test}

All tests were carried out at a test frequency of $20 \mathrm{~Hz}$ with a load R-ratio equal to -1 . Fatigue tests were conducted using the "step" technique proposed by Maxwell and Nicholas [10]. Each specimen was loaded via a series of constant amplitude block loads. The initial stress amplitude 
was chosen to be slightly less than the expected fatigue strength at $10^{6}$ cycles. For a given block, if the specimen did not fail in less than $10^{6}$ cycles the stress amplitude was increased for the following block. This was repeated until the specimen fails in less than $10^{6}$ cycles (See Fig. 3 . The endurance limit was then assumed to be the applied stress amplitude of the final block. This assumption was verified by microscopic observations of the specimen surfaces between loading blocks. No damage in the form of micro-cracks or the appearance of slip bands was observed prior to the final block loading in which the specimen failed.

To define the fatigue strength of the sheet material under shear loads, an original fatigue test apparatus was developed (Fig.4). It is based on the work of Galtier et Weber [11]. Using a uniaxial servo-hydraulic fatigue testing machine and the specimen geometry shown in Figure 5 it is possible to generate a cyclic pure shear stress state in an zone of approximately $10 \mathrm{~mm}$ in diameter (see Figure 77).Note that the geometry of the specimen has been defined using finite element calculations. The objectives were to obtain a large zone of pure shear stress (about 10mm in diameter) in the centre of the specimen and to ensure that the failure of the specimen occurs in this zone. The Von Mises equivalent stress ratio between the specimen centre and edge of the specimen is approximately 1.5. As per classical torsion loads, two planes of maximum shear stress and two planes of maximum normal stress exist in this specimen (Fig.7). Hemispherical artificial surface defects were created in the center of the critical zone of the specimens via ElectroDischarge Machining (EDM) after manual polishing of the zone. The specimens were polished, quenched (if applicable) and then the defects were machined via EDM. A cross-sectional view of a typical artificial defect is given in Fig 8 . In order to verify that residual stresses introduced via the Electro-Discharge Machining (EDM) of the defects do not affect the results, two untreated specimens have been stress relieved via a heat treatment of 1 hour at $500^{\circ} \mathrm{C}$, prior to testing.

\subsection{Fatigue test results and damage mechanisms}

For the untreated material loaded in shear with a defect size of $100 \mu m$ and for the tensile tests with a defect size of $250 \mu \mathrm{m}$, the fatigue strength obtained after stress relieving is similar to that obtained without this treatment (Tab,3). From this result it was concluded that even if residual stresses have been introduced during the EDM process they do not have an effect on the fatigue 
strength of the material in the initial or untreated state. Concerning the plain quenched material, a preliminary study of the residual stresses using the X-ray diffraction technique also showed that close to the fatigue limit, the residual stresses are significantly relaxed during cycling. Hence, the effect of residual stresses induced by quenching and/or polishing has been neglected in this work.

\subsection{Fatigue damage mechanisms}

\subsubsection{Tensile loads}

For all specimens loaded via fully reversed tensile loads, crack initiation occurred at either natural or artificial defects. The failure surface is a plane orientated at $90^{\circ}$ to the loading direction. This plane corresponds to the plane of maximum normal stress.

More precisely, for untreated specimens, without artificial defects, loaded in tension, crack initiation occurred at a surface inclusion (for which the inclusion may or may not have been pulled out) (Fig 9). For treated specimens with defects less than $100 \mu \mathrm{m}$, loaded in tension, crack initiation occurred at subsurface inclusions (Fig.9). This type of fatigue failure surface is often observed in high strength steels [12, 13] and is often associated with the Very High Cycle Fatigue domain(VHCF) for different types of material: aluminium alloys from the AlSi and $\mathrm{AlMgSi}$ families, copper and titanium alloys and also for the magnesium alloy AZ 91 [14, 15, 16, 17].

The change in damage mechanism observed in tension between the two different microstructures (i.e. for untreated and quenched specimens) is complex because it is caused by the competition between crack initiation/propagation from the surface and from inclusion in the bulk material. This phenomenon depends on many parameters (i.e. load intensity, load type, load ratio, number of cycles to failure, residual stresses, etc.) and is still very much an open topic which has been discussed in recent publications [18, 19, 20].

\subsubsection{Shear loads}

For the untreated material loaded in shear with defects less than $100 \mu m$ in diameter, fatigue cracks initiated in the material matrix typically at $0^{\circ}$ and $90^{\circ}$ to the loading direction (Fig 10 a) ). This corresponds to the classical fatigue crack initiation mechanism in which micro-cracks form on a critical plane (or planes of maximum shear stress amplitude), in the weakest and/or most 
favourably orientated grains. Both in-situ observations of the specimen surfaces and SEM observations of the failure surfaces (Fig 10 ) showed that the crack initiation sites are not associated with the presence of non-metallic inclusion. The mechanisms observed for shear load are different to those observed for tensile loads. In tension the hydrostatic stress or the maximum normal stress on the critical plane is high and initiation occurs from inclusions. In shear, these quantities are lower; causing the defect sensitivity associated with this loading condition is reduced. Hence, initiation occurs in the material matrix.This change in damage mechanism as a function of the applied loading condition (i.e. torsion or bending) has also been observed and discussed by Endo and Murakami [21]

For the untreated material loaded in shear with defects of $100 \mu m$ in radius, observations showed that two different fatigue crack initiation mechanisms can simultaneously occur. These are:

1. Crack initiation in the material matrix as discussed above without defects. This typically occurs on planes at $0^{\circ}$ and $90^{\circ}$ to the loading direction (Fig,7, Fig.11)

2. Crack initiation from the artificial defects. The cracks typically propagate on planes oriented at $45^{\circ}$ to the loading direction, or planes of maximum normal stress (Fig,7, Fig, 11.

For all shear tests with an artificial defect size greater than $100 \mu \mathrm{m}$, crack initiation occurred exclusively from the artificial defect and the cracks propagate on planes at $45^{\circ}$ to the loading direction (or planes of maximum normal stress) (Fig.7).

\subsubsection{Fatigue strength}

Figure 12 shows all of the experimental data plotted on a Kitagawa type diagram [22], with the experimentally determined fatigue strength plotted as a function of the defect size for the two materials and loading conditions. It can been seen that the the critical defect size is approximately $100 \pm 50 \mu \mathrm{m}$ and that it does not depend on hlthe loading type or the microstructure (i.e. quenched and untreated).

However, for large defects in a defect size range of $100 \mu m$ to $300 \mu m$, the quenched material is more defect sensitive than the untreated material. That is, for the quenched material the fa- 
tigue strength decrease more quickly with increasing defect size when compared to the untreated material.

Concerning the shear/tension fatigue strength ratio for the untreated material without artificial defects or defects smaller than $100 \mu m$ this ratio is equal to $\tau_{a} / \sigma_{a}=0.69$ and is a typical value for ductile steels [23]. For the quenched material this ratio is much higher $\tau_{a} / \sigma_{a}=0.82$. This corresponds to typical values for brittle materials and is close to the value reported by Palin-Luc et al. [23] for spheroidal graphite cast iron of 0.9 .

Concerning the shear/tension fatigue strength ratio for large defects, $\tau_{a}(250 \mu m) / \sigma_{a}(250 \mu m)=$ 0.7 and is the same for the untreated and the quenched materials. This value is in accordance with the Murakami approach predictions [24].

Concerning the slope of the line in a defect size range of $100 \mu \mathrm{m}$ to $300 \mu \mathrm{m}$, the slope does not depend on the type of loading but it is lower for the untreated material $\left(\frac{\Delta \sigma_{1 a}}{\Delta a}=\frac{-1}{6}\right)$ than for the quenched material $\left(\frac{\Delta \sigma_{1 a}}{\Delta a}=\frac{-1}{3}\right)$, see Fig.??. A slope of $(-1 / 6)$ is in accordance with the Murakami criterion and $(-1 / 3)$ is close to the value of $(-1 / 2)$ used in the classical LEFM approach.

For materials without artificial defects, from the experimental results and by assuming that the fatigue strength is a linear function of the hardness, the fatigue strength for tensile loads and shear loads can be defined respectively by:

$$
\sigma_{w}=1.1 H V+70 \quad \text { and } \quad \tau_{w}=1.12 H V-30
$$

\section{A probabilistic multiaxial fatigue criterion and a Kitagawa diagram to reflect the relation between hardness and fatigue strength}

The aim of this section is to propose an evolution of the probabilistic model proposed by Pessard et al. [25, 26] in order to model the effect of the heat treatment and the presence of defects on the fatigue behaviour of the $22 \mathrm{MnB} 5$ steel. The principal hypothesis of this criterion is that two different fatigue damage mechanisms coexist (i.e. initiation from defects or initiation in the matrix material). This assumption has been verified for the untreated material with a defect of $100 \mu m$ where two different mechanisms have been observed (see Fig 11). To model the two damage mechanisms, two different fatigue criteria must be chosen. The threshold defined by each one of 
these criteria is then re-defined in terms of a Weibull distribution[27], giving a failure probability caused by each of these mechanisms.

To predict crack initiation for materials without defects, an equivalent stress and a stress threshold are used. $\sigma_{t h 01}$ is the scale parameter and $m_{1}$ is the shape parameter (or the Weibull exponent) used to reflect the scatter associated with the threshold stress and by consequence the scatter associated with the fatigue damage mechanism. The probability of microcrack initiation in a grain corresponds to the probability of finding a grain with a threshold stress $\sigma_{t h}$ that is less than the applied equivalent stress $\sigma_{e q}(\operatorname{See} \mathrm{Tab} 4)$.

To predict crack propagation from a defects, the classical LEFM approach to predict fatigue behaviour is used. A crack will not propagate under cyclic loading if its stress intensity range, $\Delta K$, is less than the crack propagation threshold, $\Delta K_{t h}$. As before, the inherent stochastic character of the propagation threshold will be modelled using a second Weibull distribution (See Tab.4).

Finally, the survival probability of an entire component, due to both damage mechanisms, is equal to the product of the two survival probabilities. Essentially, the weakest link hypothesis [28], is employed, which assumes that the two damage mechanisms are independent (See Tab,4).

The scale effect is explicitly taken into account via the terms $\frac{S_{\Omega 1}}{S_{01}}$ and $\frac{S_{\Omega 2}}{S_{02}}$. In the following, for reasons of simplicity, the scale effect will not be considered, which corresponds to the assumption that the results presented below are for specimens with approximately the same surface area. The total failure probabilities can be simplified to:

$$
P_{F}=1-\exp \left\{-\left[\left(\frac{\sigma_{e q}}{\sigma_{t h 01}^{\prime}}\right)^{m_{1}}+\left(\frac{\Delta K}{\Delta K_{t h 02}^{\prime}}\right)^{m_{2}}\right]\right\}
$$

Where

$$
\sigma_{t h 01}^{\prime}=\sigma_{t h 01}\left(\frac{S_{01}}{S_{\Omega 1}}\right)^{1 / m_{1}} \quad \text { and } \quad \Delta K_{t h 02}^{\prime}=\Delta K_{t h 02}\left(\frac{S_{02}}{S_{\Omega 2}}\right)^{1 / m_{2}}
$$

\section{Application using the Papadopoulos and LEFM criteria combination}

For the $22 \mathrm{MnB} 5$ steel, the first mechanism concerning crack initiation in the material matrix without defects (or from very small defects) is modeled using the Papadoupolos multiaxial criterion [29]. This approach is based on the hypothesis of elastic shakedown at the mesoscopic 
scale. It considers that crack initiation is related to local plasticity within an isolated, unfavourably orientated grain. The Papadopoulos criterion can be defined by :

$$
\sigma_{e q}=\sqrt{\left\langle T_{a}^{2}\right\rangle}+k^{\prime} \sigma_{H, \max } \geqslant \sigma_{t h}^{\prime}
$$

To take into account the effect of the heat treatment on the fatigue strength it is necessary to define the two scale factors of the two Weibull distributions $\sigma_{t h 01}^{\prime}$ and $\Delta K_{t h 02}^{\prime}$ in terms of a material parameter that is representative of the heat treatment. The scale factor of the Weibull distribution describing the threshold value of the criterion for the first mechanism is calculated from the evolution of the fatigue strength in shear as a function of hardness (Eq. 11), $\sigma_{t h 01}^{\prime}$ and is is assumed to be proportional to the hardness:

$$
\sigma_{t h 01}^{\prime} \Gamma\left(1+\frac{1}{m}\right)=\alpha H V+\beta
$$

Where $\Gamma(t)=\int_{0}^{\infty} x^{t-1} e^{-x}$ is the gamma function [30]. From the experimental results, $\alpha$ and $\beta$ can be identified as $\alpha=1.12$ and $\beta=-30 M P a$.

Assuming that the evolution of the fatigue strength in tension as a function of the Hardness is also linear (Eq. 1), the following expression for the evolution of $k^{\prime}$ with the hardness can be calculated as:

$$
k^{\prime}=\frac{3(1.12 H V-30)}{(1.1 H V+70)}-\frac{3}{2}
$$

This expression for the parameter defining the sensitivity to the hydrostatic stress $k^{\prime}$ makes it possible to take into account the evolution of the ratio $\sigma_{w} / \tau_{w}$ with the experimentally observed hardness.

Concerning the second damage mechanism (i.e. crack propagation from defects), for fully reversed uniaxial tensile loads, if the phenomenon of crack closure is neglected and if the crack propagation is assumed to be predominately in Mode I from a semi-circular surface crack, based on LEFM, Murakami [24] proposed to approximate the stress intensity factor in mode I by:

$$
K_{I} \approx 0.65 \sigma_{I} \sqrt{\pi \sqrt{\text { area }}} \quad \rightarrow \quad \Delta K=1,45 \sigma_{I, a} \sqrt{\pi a}
$$


With the same assumptions, for shear loads, with a shape factor of $F=0.84$, the relations becomes:

$$
K_{I} \approx F \tau_{I} \sqrt{\pi \sqrt{\text { area }}} \quad \rightarrow \quad \Delta K=1,88 \sigma_{I, a} \sqrt{\pi a}
$$

It is assumed that the scale factor of the Weibull distribution defining the threshold value of the second damage mechanism is a linear function of the hardness, so that:

$$
\Delta K_{t h 02}^{\prime} \Gamma\left(1+\frac{1}{m}\right)=\eta H V+\delta
$$

After identification from experimental results, $\eta=0.027$ and $\delta=-3.57 \mathrm{MPa} \sqrt{m}$.

For the sake of simplicity it will be assumed that the two damage mechanisms are characterised by the same degree of scatter. This is equivalent to assuming that the Weibull shape parameters are the same (or $m=m_{1}=m_{2}=25$ ). By substituting equations 4 and 8 into equation 2 , the following expression for the fatigue strength for shear load as a function of the probability of failure, and the crack length, can be established:

$$
\sigma_{I, a}\left(P_{F}, a\right)=\left[\frac{\ln \left(\frac{1}{1-P_{F}}\right)}{\left(\frac{1}{\sigma_{t h 01}^{\prime}}\right)^{m}+\left(\frac{1.88 \sqrt{\pi a}}{\Delta K_{t h 02}^{\prime}}\right)^{m}}\right]^{\frac{1}{m}}
$$

Note that the fatigue life, for which $P_{F}=0.5$ is given by:

$$
\sigma_{I, a}\left(P_{F}=0.5, a\right)=\left[\frac{\ln (2)}{\left(\frac{1}{\sigma_{t h 01}^{\prime}}\right)^{m}+\left(\frac{1.88 \sqrt{\pi a}}{\Delta K_{t h 02}^{\prime}}\right)^{m}}\right]^{\frac{1}{m}}
$$

The predictions for the two different loading types lead to different Kitagawa diagrams (Fig.14). It is also possible to obtain different Kitagawa diagrams for different hardness levels (Fig.15). This type of diagrams could be very useful for the design of heat treated components with variable hardness. It should be noted that in this work only tensile and shear loads have been investigated, however it is possible to generalise the approach for combined tension-torsion loads using a expression for the stress intensity factor that is suitable for more complex loads [25]. 


\section{Evolution for large range of hardness}

The previous section was focused on the $22 \mathrm{MnB} 5$ steel with two different microstructural states (untreated and quenched). It was assumed in the previous section that the relationship between the hardness and the fatigue strength is linear. However, experimental results taken from the literature [14, 31, 32] show that the fatigue strength increases linearly with increasing hardness, up until a certain value, after which the fatigue strength drops (see Figure 16). The objective in this section is to highlight the flexibility of the proposed approach by using a more complex expression for the crack propagation threshold, taken from the literature [31]. This expression is valid for a large crack size range and material hardness range and permit to model the evolution experimentaly observed.

For the sake of simplicity only fully reversed uniaxial pushpull loads are investigated in conjunction with the same criteria as those used in the original Kitagawa-Takahashi diagram. Consequently, a probabilistic uniaxial Kitagawa-Takahashi diagram in function of the hardness are generated.

\subsection{For uniaxial fully reversed tension-compression loads}

The two criteria chosen are (a) the simple stress amplitude criterion and (b) the LEFM criterion, for which it is assumed that the opening mode (Mode I) is the dominate crack propagation driving force. These criteria are described by the following equations:

$$
\sigma_{e q}=\sigma_{I, a} \geqslant \sigma_{w} \quad \text { and } \quad \Delta K=1,45 \sigma_{I, a} \sqrt{\pi a} \geqslant \Delta K_{t h}
$$

As postulate in the previous section, the threshold $\sigma_{t h 01}^{\prime}$ of the first mechanism is assumed to be proportional to the hardness (Eq. 5).

Concerning the second mechanism, crack propagation from defects, Murakami [24] proposed an equation that can take into account the effect of the hardness and defects size on the propagation threshold. It has been shown in the literature [14, 31, 33, 34] that the Murakami criterion is appropriate for modelling small defects where the propagation fatigue threshold increases with the crack size and hardness. For long cracks or for materials with high hardness the problem 
is different and the crack propagation threshold does not depend on the crack size and tends to decrease with the hardness. Chapetti [31] proposed a new expression for the crack propagation threshold for high strength steel in the very high cycle domain. To take into account the hardness on the crack propagation threshold for a large range of hardnesses and crack sizes, the author proposed to define the crack propagation threshold $\Delta K_{t h}$ as being equal to the lower value given by:

$$
\begin{gathered}
\Delta_{K t h}=4 \cdot 10^{-3}(H V+120) a^{1 / 3} \\
\Delta_{K t h-1}=\Delta K_{t h-\max }-\gamma H V
\end{gathered}
$$

where $\Delta K_{t h-\max }$ is the maximum crack propagation threshold and $\gamma$ a material parameter. Note that the original expression proposed by Chapetti [31] was a function of the ultimate tensile stress (UTS) and not the hardness.

\subsection{Application to data from the literature}

In this section, the proposed model is compare to that of Pang et al. [14]. From numerous data available in the literature for tests conducted on a 4340 steel, Pang et al. proposed a general relation between the tensile strength and the fatigue strength of metallic materials. Based on the idea that the fatigue strength is the result of a competition between fatigue crack initiation sites and crack propagation from defects, the authors propose a parabolic law $\sigma_{w}=\sigma_{u}\left(C-P \sigma_{u}\right)$. The parameter $\mathrm{P}$ used in this empirical expression is defined by the authors as a defect sensitivity parameter. The assumptions used by Pang et al. are very similar to those of the approach proposed here. The originality in our work however is that a probabilistic framework is used to model the competition between the two observed damage mechanisms.

An evolution of the proposed probabilistic model, using the Chapetti [31] crack propagation threshold expression, is presented below. The experimental data from Garwood et al. [32] are used to identify the model parameters and to analyse the resulting predictions $\left(\sigma_{w}=1.5 \mathrm{HV}, \Delta K_{\text {th-max }}=\right.$ $12 M P a \sqrt{m}$ and $\gamma=0.007)$.

Plotting the Kitagawa diagram and the fatigue strength as a function of hardness (Fig 17) allows us to understand the effect of the change in the damage mechanism on the fatigue strength 
and to defined three domains.

- Zone 1: When the defect size is small and/or the hardness is low (equivalent to considering material without defect) the relation between the fatigue strength and the hardness is linear, only the first mechanism occurs (micro-plasticity in the material matrix).

- Zone 2: When the defect size and/or the hardness increase, a second type of damage mechanisms occurs (i.e. propagation from small defects or cracks) and the fatigue strength increase with the hardness.

- Zone 3: When the defect size and/or the hardness become very high, a third type of behaviour occurs, the fatigue strength decreases with the hardness.

As shown in Figure 18, one of the advantages of this approach is that the evolution of the fatigue strength can be directly plotted as a function of the hardness for different probabilities of failure using equation 11 . The fatigue strength predictions as a function of the hardness show a similar trend when compared to the experimental results obtained by Garwood et al. for different steels (see Figure 16, 17, and 18).

\section{Conclusions}

The principal conclusions of this work can be summarised as follows:

- An original fatigue test apparatus has been developed to test the sheet metal in shear. With this apparatus both the fatigue strength and damage mechanisms associated with the shear loading condition have been identified. Fatigue cracks in shear can initiate either at artificial defects or due to meso-plasticity in the material matrix.

- The critical defect size is determined to be $100 \pm 50 \mu m$ for the $22 \mathrm{MnB} 5$ steel and does not depend on the loading type or material microstructure (i.e. quenched and untreated). However, for large defects, the quenched material is more sensitive to the defect size when compared to the untreated material. For a defect size range of $100 \mu m$ to $300 \mu m$ the slope of the Kitagawa-Takahashi diagram is approximately $-1 / 3$ and $-1 / 6$ for the quenched and untreated materials respectively and doesn't depend on the loading type. 
- The proposed model can be used to take into account both the heat treatment (via the hardness) and the defect sensitivity on the fatigue strength of the 22MnB5 steel. It leads to a probabilistic Kitagawa type diagram that can explain the experimental evolution of the fatigue strength. The approach is able to take into account the observed change in fatigue damage mechanism and explains the evolution of the fatigue strength as a function of the Vickers hardness.

\section{References}

[1] Mar'yanovskaya TS, Kurashvili SY. Effect of alloying with boron and cerium on the fatigue strength of manganese steel. Met Sci Heat Treat 1968;10:549-51.

[2] Karbasian H, Tekkaya AE, A review on hot stamping, J Mater Process Technol 2010;210:2103-18.

[3] Liu H, Xing Z, Lei C. Hot formation quality of high strength steel BR1500HS for hot stamping without cooling system. Trans. Nonferrous Met. Soc. China 2012;22:542-47.

[4] Bardelcik A, Salisbury CP, Winkler S, Wells MA, Worswick MJ. Effect of cooling rate on the high strain rate properties of boron steel. Int J Imp Eng 2010;37:694-702.

[5] Merklein M, Lechler J. Investigation of the thermo-mechanical properties of hot stamping steel. J Mater Process Technol 2006;177:452-5.

[6] Geary W, King JE. Residual stress effects during near-threshold fatigue crack growth. Int J Fatigue 1987;9:116.

[7] Palin-Luc T., Coupard D., Dumas C., Bristiel P., Simulation of multiaxial fatigue strength of steel component treated by surface induction hardening and comparison with experimental results, Int J fatigue 2011;33:10407.

[8] Komotori J, Shimizu M, Misaka Y, Kawasaki K. Fatigue strength and fracture mechanism of steel modified by super-rapid induction heating and quenching. Int $\mathrm{J}$ fatigue 2001;23:225-30.

[9] Song SH, Choi BH. Fatigue characteristics and fatigue limit prediction of an induction case hardened CrMo steel alloy. Mater Sci Eng A 2003;361:15-22.

[10] Maxwell DC, Nicholas T. A rapid method for generation of a Haigh diagram for high cycle fatigue. In: Panontin TL, Sheppard SD, editors. Fatigue and fracture mechanics, ASTM STP 1321, vol. 29. West Conshohocken (PA): American Society for Testing and Materials; 1999; p. 626-641.

[11] Galtier A, Weber B. Fatigue tests on thin sheet materials. International conference on fatigue design, Paris, 2005.

[12] Sun C, Lei Z, Xie J, Hong Y.Effects of inclusion size and stress ratio on fatigue strength for high-strength steels with fish-eye mode failure. Int J fatigue 2013;48:19-27. 
[13] Murakami Y, Nomoto T, Ueda T. Factors influencing the mechanism of superlong fatigue failure in steels. Fatigue Fract Eng Mater Struct 1999;22:581-90.

[14] Pang JC, Li SX, Wang ZG, Zhang ZF. General relation between tensile strength and fatigue strength of metallic materials. Mater Sci Eng A 2013;564:331-41.

[15] Nishijima S, Kanazawa K. Stepwise SN curve and fish-eye failure in gigacycle fatigue. Fatigue Fract Eng Mater Struct 1999;22:601-7.

[16] Zhu K, Jones JW, Mayer H, Lasecki JV, Allison JE. Effects of microstructure and temperature on fatigue behavior of E319-T7 cast aluminum alloy in very long life cycles. In: Sakai T, Ochi Y, editors. Proc of 3rd int conf on very high cycle fatigue, VHCF-3, Kusatsu, Japan: The Soc of Materials Science 2004, p.553-560.

[17] Berger C, Pyttel B, Trossmann T. Very high cycle fatigue tests with smooth and notched specimens and screws made of light metal alloys. In: Sakai T, Ochi Y,editors. Proc of 3rd int conf on very high cycle fatigue, VHCF-3, Kusatsu, Japan: The Soc of Materials Science; 2004, p.561-568.

[18] Park S H, Hong S G, Chun Y S, Lee Y H, Lee C S. High-cycle fatigue characteristics of non-heat-treated steels developed for bolt applications, Mater Sci Eng, A 2012;550:118-24.

[19] Shiozawa K, Hasegawa T, Kashiwagi K, Lu L.Very high cycle fatigue properties of bearing steel under axial loading condition, Int. J. Fatigue 2009;31:880-8.

[20] Shiozawa K, Murai M, Shimatani Y, Yoshimoto T. Transition of fatigue failure mode of Ni-Cr-Mo low-alloy steel in very high cycle regime, Int. J. Fatigue 2010;32:541-50.

[21] Endo M, Murakami Y. Effect of an artificial small defect on torsional fatigue strength of steels, J. Eng. Mater. Technol. 1987;109:124-9.

[22] Kitagawa H, Takahashi S. Applicability of fracture mechanics to very small cracks. In: ASM Proceedings of 2nd international conference on mechanical behaviour of materials. Metalspark, Ohio; 1976;p.627-731

[23] Palin-Luc T, Lasserre S. An energy based criterion for high cycle multiaxial fatigue. Eur. J. Mech. A/Solids 1998;2:237-51.

[24] Murakami Y. Metal Fatigue:effects of small defects and non-metallics inclusion. London:Elsevier;2002.

[25] Pessard E, Bellett D, Morel F, Koutiri I. A mechanistic approach to the Kitagawa-Takahashi diagram using a multiaxial probabilistic framework. Eng Fract Mech 2013;109:89-104.

[26] Pessard E, Morel F, Morel A, Bellett D. Modelling the role of non-metallic inclusions on the anisotropic fatigue behaviour of forged steel, Int J Fatigue 2011;33:568-77.

[27] Weibull W. A statistical distribution function of wide applicability. ASME J Appl Mech. 1951;18:293-7.

[28] Freudenthal AM, in: H. Liebowitz (Eds.), Fracture vol 2, Academic Press, New York, 1968, p.591-619.

[29] Papadopoulos IV, Fatigue limit of metals under multiaxial stress conditions: the microscopic approach, ISEI/IE 2464/93, Commission of the European Communities Joint Research Center, 1993.

[30] Abramowitz M, Stegun A. Handbook of Mathematical Functions. New York:Dover;1965. 
[31] Chapetti MD, A simple model to predict the very high cycle fatigue resistance of steels, Int $\mathbf{J}$ Fatigue 2011;33:833-41.

[32] Garwood MF, Gensamer M, Zurburg HH, Burwell JT, Erickson MA, La Que FL. Interpretation of Tests and Correlation with Service, American Society for Metals, 1951.

[33] Kondo Y, Sakae C, Kubota M, Kudou T, The effect of material hardness and mean stress on the fatigue limit of steels containing small defects relationship and the short fatigue crack threshold, Fatigue Fract Eng Mater Struct $2003 ; 26: 675-82$.

[34] McEvily AJ, Endo M, Murakami Y. On the $\sqrt{\text { area }}$ relationship and the short fatigue crack threshold.Fatigue Fract Eng Mater Struct 2003;26:269-278. 


\begin{tabular}{c|c|c|c|c|c|c|c|c|c|c|c} 
Element & $\mathrm{C}$ & $\mathrm{Mn}$ & $\mathrm{Si}$ & $\mathrm{P}$ & $\mathrm{Si}$ & $\mathrm{Al}$ & $\mathrm{Cr}$ & $\mathrm{B}$ & $\mathrm{Ti}$ & $\mathrm{N}$ & $\mathrm{Mo}$ \\
\hline Weigth (\%) & 0.0206 & 1.1191 & 0.264 & 0.019 & 0.007 & 0.02 & 0.199 & 0.002 & 0.02 & - & 0.003
\end{tabular}

Table 1: Chemical composition of the 22MnB5 steel

\begin{tabular}{l|c|c|c|c} 
& $\begin{array}{c}\text { Ultimate Tensile } \\
\text { Stress (MPa) }\end{array}$ & $\begin{array}{c}\text { Yield Stress } \\
(\mathrm{MPa})\end{array}$ & $\begin{array}{c}\text { Tensile } \\
\text { Elongation (\%) }\end{array}$ & $\begin{array}{c}\text { Surface Hardness } \\
\text { HV20 }\end{array}$ \\
\hline Untreated & 580 & 415 & 25 & 180 \\
Quenched & 1580 & 1140 & 5 & 600
\end{tabular}

Table 2: Mechanical properties of the 22MnB5 steel 


\begin{tabular}{|c|c|c|c|c|c|c|c|c|}
\hline \multirow{2}{*}{$\begin{array}{l}\text { Specimen } \\
\text { Name }\end{array}$} & \multirow{2}{*}{$\begin{array}{l}\text { Artificial Defect Size } \\
\text { Radius in } \mu m\end{array}$} & \multicolumn{2}{|c|}{ Loading at Failure (MPa) } & \multicolumn{3}{|l|}{ Step } & \multirow{2}{*}{$\begin{array}{l}N_{f} \\
\left(\times 10^{5}\right)\end{array}$} & \multirow{2}{*}{$\begin{array}{l}\sqrt{\text { area }} \\
(\mu m) \\
\end{array}$} \\
\hline & & Type & Amplitude $(\mathrm{R}=-1)$ & Number & Cycles/step & $\mathrm{MPa} / \mathrm{step}$ & & \\
\hline $\mathrm{Te}-1$ & 0 & $\sigma_{a}$ & 280 & 2 & $10^{6}$ & 20 & 5.37 & $9^{b}$ \\
\hline $\mathrm{Te}-2$ & 0 & $\sigma_{a}$ & 270 & 1 & $10^{6}$ & $\mathrm{~N} / \mathrm{A}$ & 2.28 & $12^{b}$ \\
\hline $\mathrm{Te}-3$ & 0 & $\sigma_{a}$ & 270 & 1 & $10^{6}$ & N/A & 4.51 & $28^{b}$ \\
\hline $\mathrm{Te}-4$ & 50 & $\sigma_{a}$ & 280 & 6 & $10^{6}$ & 20 & 4.57 & 63 \\
\hline $\mathrm{Te}-5$ & 50 & $\sigma_{a}$ & 280 & 2 & $10^{6}$ & 20 & 0.56 & 63 \\
\hline Te-6 & 100 & $\sigma_{a}$ & 260 & 4 & $10^{6}$ & 20 & 5.16 & 125 \\
\hline $\mathrm{Te}-7$ & 100 & $\sigma_{a}$ & 260 & 2 & $10^{6}$ & 20 & 3.99 & 125 \\
\hline Te- 8 & 250 & $\sigma_{a}$ & 220 & 4 & $10^{6}$ & 20 & 4.37 & 313 \\
\hline Te-9 & 250 & $\sigma_{a}$ & 220 & 2 & $10^{6}$ & 20 & 0.92 & 313 \\
\hline $\mathrm{Te}-10^{c}$ & 250 & $\sigma_{a}$ & 220 & 2 & $10^{6}$ & 20 & 3.99 & 313 \\
\hline Sh-1 & 0 & $\tau_{a}$ & 190 & 4 & $10^{6}$ & 20 & 3 & I \\
\hline Sh-2 & 0 & $\tau_{a}$ & 190 & 3 & $10^{6}$ & 20 & 5 & I \\
\hline Sh-3 & 100 & $\tau_{a}$ & 170 & 3 & $10^{6}$ & 20 & 3.50 & 125 \\
\hline $\mathrm{Sh}-4^{c}$ & 100 & $\tau_{a}$ & 170 & 3 & $10^{6}$ & 20 & 3.58 & 125 \\
\hline Sh-5 & 250 & $\tau_{a}$ & 160 & 4 & $10^{6}$ & 20 & 4.15 & 313 \\
\hline Sh-6 & 250 & $\tau_{a}$ & 150 & 2 & $10^{6}$ & 10 & 3.50 & 313 \\
\hline Sh-7 & 375 & $\tau_{a}$ & 140 & 2 & $10^{6}$ & 20 & 9.60 & 665 \\
\hline Sh-8 & 375 & $\tau_{a}$ & 140 & 3 & $10^{6}$ & 10 & 2.10 & 665 \\
\hline Te-1 HT & 0 & $\sigma_{a}$ & 800 & 2 & $2.10^{5}$ & 20 & 1.37 & $25^{b}$ \\
\hline Te-2 HT & 0 & $\sigma_{a}$ & 720 & 2 & $10^{6}$ & 40 & 4.05 & $33^{b}$ \\
\hline Te-3 HT & 25 & $\sigma_{a}$ & 780 & 4 & $2.10^{5}$ & 20 & 0.18 & $40^{b}$ \\
\hline Te-4 HT & 25 & $\sigma_{a}$ & 800 & 2 & $10^{6}$ & 40 & 0.96 & $4^{b}$ \\
\hline Te-5 HT & 25 & $\sigma_{a}$ & 760 & $1^{a}$ & $10^{6}$ & N/A & 0.42 & $37^{b}$ \\
\hline Te-6 HT & 100 & $\sigma_{a}$ & 720 & 7 & $2.10^{5}$ & 20 & 0.92 & 125 \\
\hline Te-7 HT & 100 & $\sigma_{a}$ & 720 & 3 & $10^{6}$ & 40 & 2.53 & 125 \\
\hline Te-8 HT & 100 & $\sigma_{a}$ & 680 & $1^{a}$ & $10^{6}$ & N/A & 0.32 & 125 \\
\hline Te-9 HT & 250 & $\sigma_{a}$ & 540 & 7 & $2.10^{5}$ & 20 & 1.39 & 313 \\
\hline Te-10 HT & 250 & $\sigma_{a}$ & 560 & 3 & $10^{6}$ & 40 & 4.4 & 313 \\
\hline Te-11 HT & 250 & $\sigma_{a}$ & 520 & $1^{a}$ & $10^{6}$ & $\mathrm{~N} / \mathrm{A}$ & 1.15 & 313 \\
\hline Sh-1 HT & 0 & $\tau_{a}$ & 640 & $1^{a}$ & $10^{6}$ & N/A & 7.38 & I \\
\hline Sh-1 HT & 25 & $\tau_{a}$ & 640 & 4 & $5.10^{5}$ & 40 & not failed & I \\
\hline Sh-2 HT & 100 & $\tau_{a}$ & 539 & 7 & $2.10^{5}$ & 20 & 1.23 & 125 \\
\hline Sh-3 HT & 100 & $\tau_{a}$ & 539 & 2 & $10^{6}$ & 20 & 1.07 & 125 \\
\hline Sh-4 HT & 250 & $\tau_{a}$ & 389 & 7 & $2.10^{5}$ & 20 & 0.701 & 313 \\
\hline Sh-5 HT & 250 & $\tau_{a}$ & 369 & 1 & $10^{6}$ & N/A & 8.83 & 313 \\
\hline \multicolumn{4}{|c|}{ Te: Tension test } & $a:$ failure be & $10^{6}$ cycles & & & \\
\hline \multicolumn{4}{|c|}{ Sh: Shearing test } & ${ }^{b}:$ measured & fracture surf & & & \\
\hline \multicolumn{4}{|c|}{ HT: Heat Treated material } & ${ }^{c}:$ after resid & l stress annec & & & \\
\hline
\end{tabular}

Table 3: Test history for all fatigue specimens 


\begin{tabular}{|l|c|c|}
\hline & Mechanism 1 & Mechanism 2 \\
\hline Threshold & $\sigma_{e q}<\sigma_{t h}$ & $\Delta K<\Delta K_{t h}$ \\
\hline $\begin{array}{l}\text { Probability den- } \\
\text { sity function }\end{array}$ & $f_{01}\left(\sigma_{t h}\right)=\frac{m_{1}}{\sigma_{t h 01}}\left(\frac{\sigma_{t h}}{\sigma_{t h 01}}\right)^{m_{1}-1} \exp \left\{-\left(\frac{\sigma_{t h}}{\sigma_{t h 01}}\right)^{m_{1}}\right\}$ & $f_{02}\left(\Delta K_{t h}\right)=\frac{m_{2}}{\Delta K_{t h 02}}\left(\frac{\Delta K_{t h}}{\Delta K_{t h 02}}\right)^{m_{2}-1} \exp -\left\{\left(\frac{\Delta K_{t h}}{\Delta K_{t h 02}}\right)^{m_{2}}\right\}$ \\
\hline $\begin{array}{l}\text { Failure probabil- } \\
\text { ity }\end{array}$ & $P_{F_{1}}=1-\exp \left[-\frac{S_{\Omega 1}}{\left.S_{01}\left(\frac{\sigma_{e q}}{\sigma_{t h 01}}\right)^{m_{1}}\right]}\right.$ & $P_{F_{2}}=1-\exp \left[-\frac{S_{\Omega 2}}{S_{02}}\left(\frac{\Delta K}{\Delta K_{t h 02}}\right)^{m_{2}}\right]$ \\
\hline $\begin{array}{l}\text { Total failure } \\
\text { probability }\end{array}$ & $P_{F}=1-\exp \left\{-\left[\frac{S_{\Omega 1}}{S_{01}}\left(\frac{\sigma_{e q}}{\sigma_{t h 01}}\right)^{m_{1}}+\frac{S_{\Omega 2}}{S_{02}}\left(\frac{\Delta K}{\Delta K_{t h 02}}\right)^{m_{2}}\right]\right\}$ \\
\hline
\end{tabular}

Table 4: Expression of the failure probabilities used in the proposed modelling framework 


\section{Figure captions}

Fig. 1: a) Rear axle beam, b) Von Mises equivalent stress (MPa) for torsion loads (from an elastic finite element simulation)

Fig. 2: Microstructure of the 22MnB5 steel, a) untreated state, b) after the heat treatment

Fig. 3: Schematic representation of the testing procedure

Fig. 4: A test apparatus for the cyclic loading of flat specimens in shear

Fig. 5: Shear specimen

Fig. 6: Tensile specimen

Fig. 7: Von Mises stress from an elastic finite element simulation (MPa)

Fig. 8: SEM observation of fatigue crack initiation sites on tensile specimens at an artificial defect $\varnothing 500 \mu m$

Fig. 9: Crack initiation sites a-b) untreated material, c-d) quenched material showing "Fish eye" fracture surfaces

Fig. 10: a) Observation on the surface of a shear specimen showing crack initiation in the material matrix on planes at $0^{\circ}$ and $90^{\circ}$ to the specimen axis, b-c) failure surface for a shear test

Fig. 11: Surface observations of a shear specimen showing two co-existing fatigue damage mechanisms (a) cracks initiation at the defect $(\varnothing 200 \mu \mathrm{m})$ and propagating on planes of maximum normal stress and (b) cracks initiating in the material matrix on slip planes at $0^{\circ}$ and $90^{\circ}$ to the specimen axis

Fig. 12: Kitagawa diagram for the 22MnB5 steel in its initial untreated state and after a quench Heat Treatment (HT) for tensile and shear loads. Defects with a size of less than $50 \mu \mathrm{m}$ are natural defects, unfilled symbol are used for unfailed specimens and filled symbol are used for failed specimens

Fig. 13: Kitagawa diagram for the 22MnB5 steel for a defect size range of 100 to $300 \mu m$, HT $=$ Heat Treated or quenched material

Fig. 14: Kitagawa diagram for the 22MnB5 steel for different loading types, the prediction are calculated using the Papadopoulos and the LEFM criteria

Fig. 15: Kitagawa diagram in tension for the 22MnB5 steel for different hardness levels, the 
prediction are calculated using the Papadopoulos and the LEFM criteria

Fig. 16: Relationship between hardness and the fatigue limit (zero mean stress)[Garwood MF, Gensamer M, Zurburg HH, Burwell JT, Erickson MA, La Que FL. Interpretation of Tests and Correlation with Service, American Society for Metals, 1951]

Fig. 17: Fatigue strength prediction in tension versus Vickers Hardness for different defect sizes, for the SAE 4340 steel

Fig. 18: Fatigue strength prediction in tension versus Vickers Hardness for different failure probabilities, a defect size of $20 \mu m$, for the SAE 4340 steel 


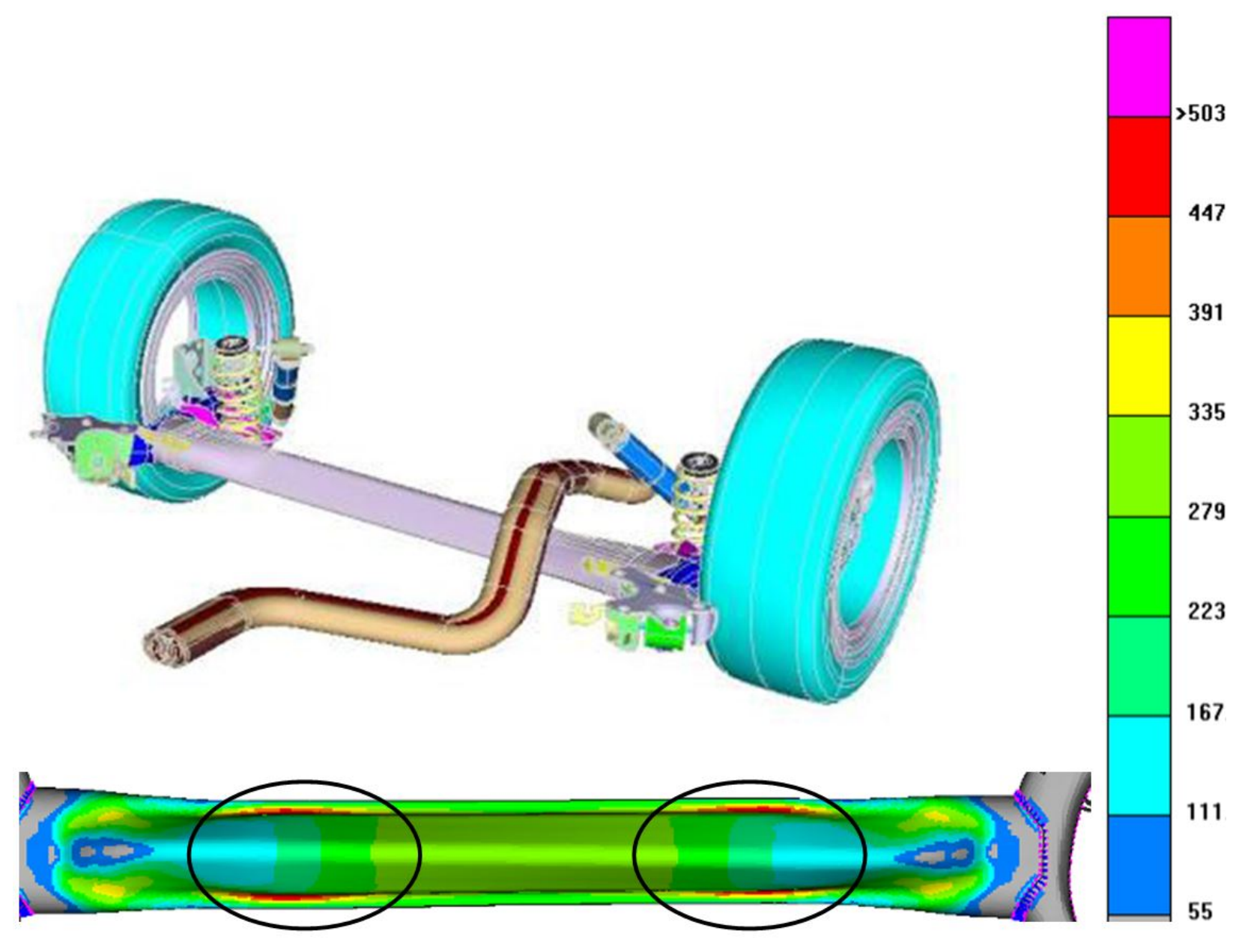

Fig. 1: a) Rear axle beam, b) Von Mises equivalent stress (MPa) for torsion loads (from an elastic finite element simulation) 

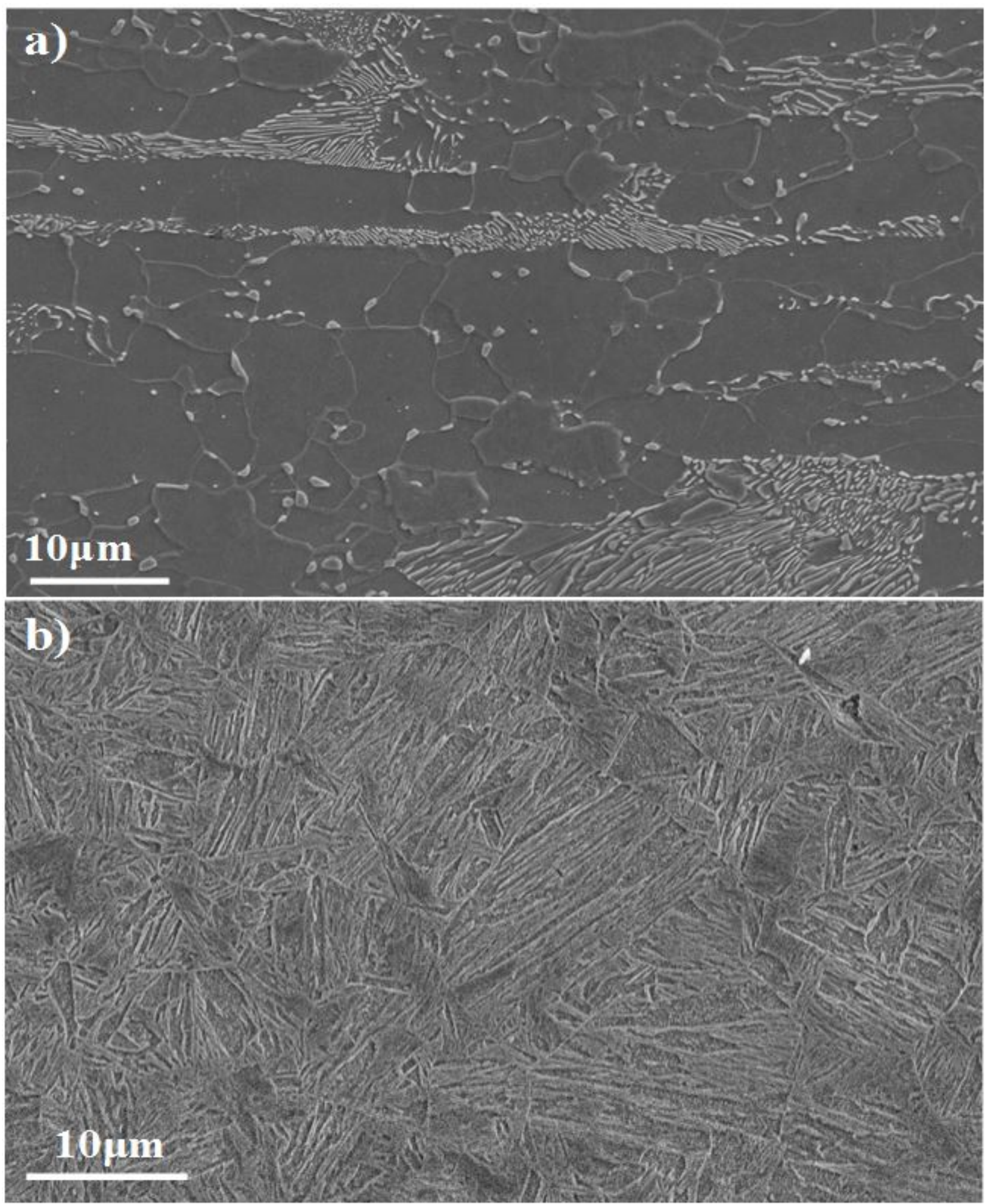

Fig. 2: Microstructure of the 22MnB5 steel, a) untreated state, b) after the heat treatment 


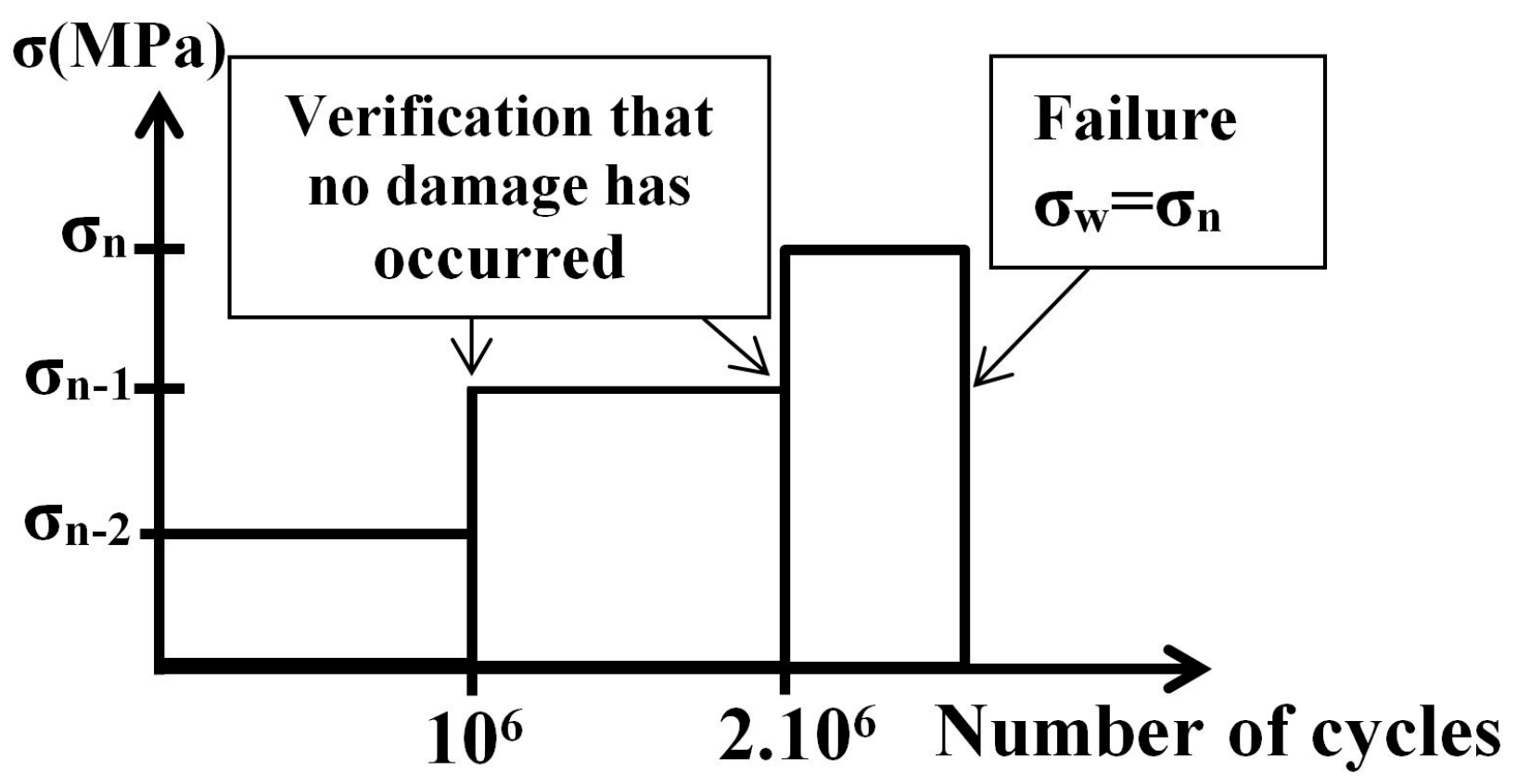

Fig. 3: Schematic representation of the testing procedure 


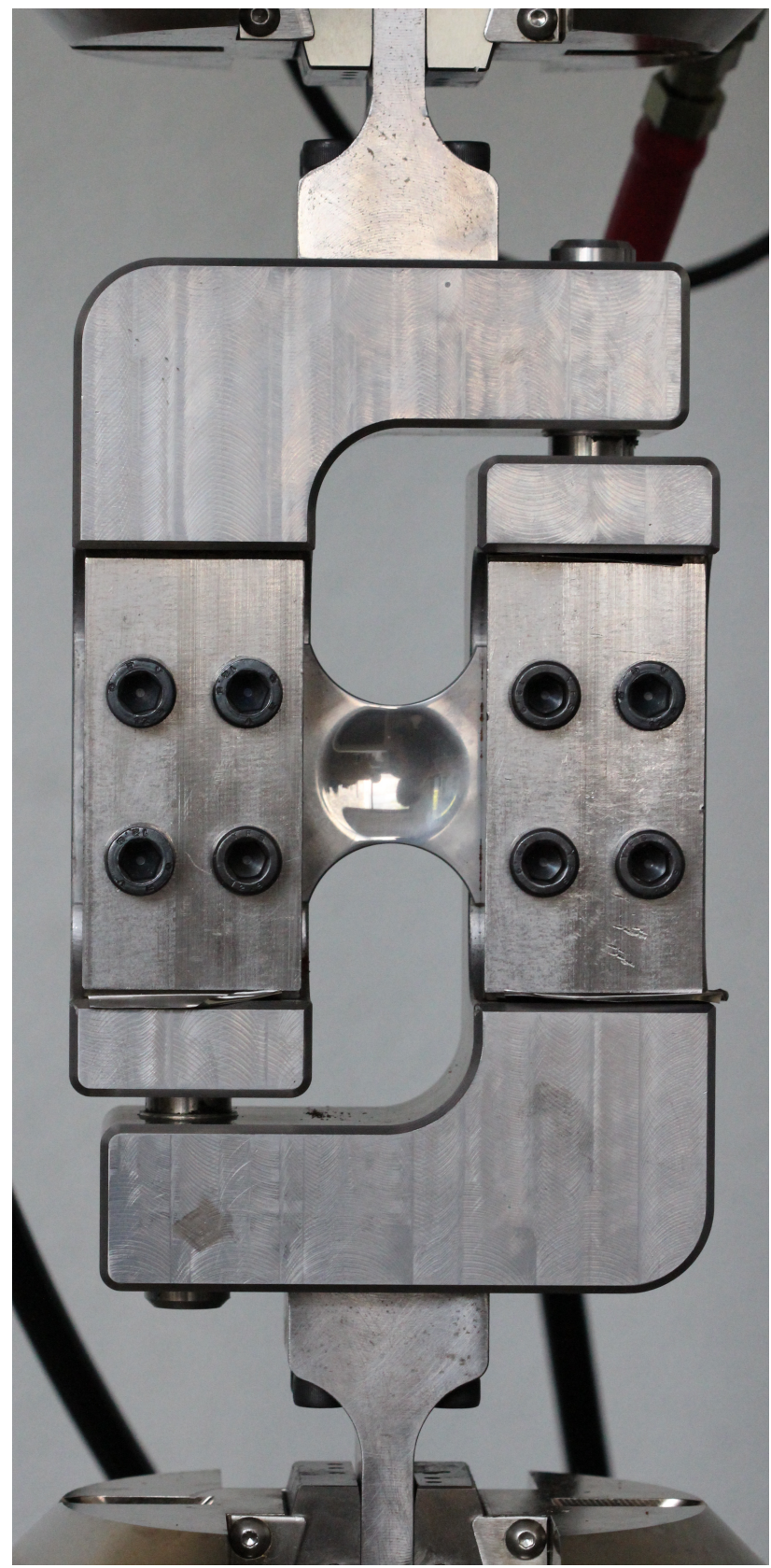

Fig. 4: A test apparatus for the cyclic loading of flat specimens in shear 


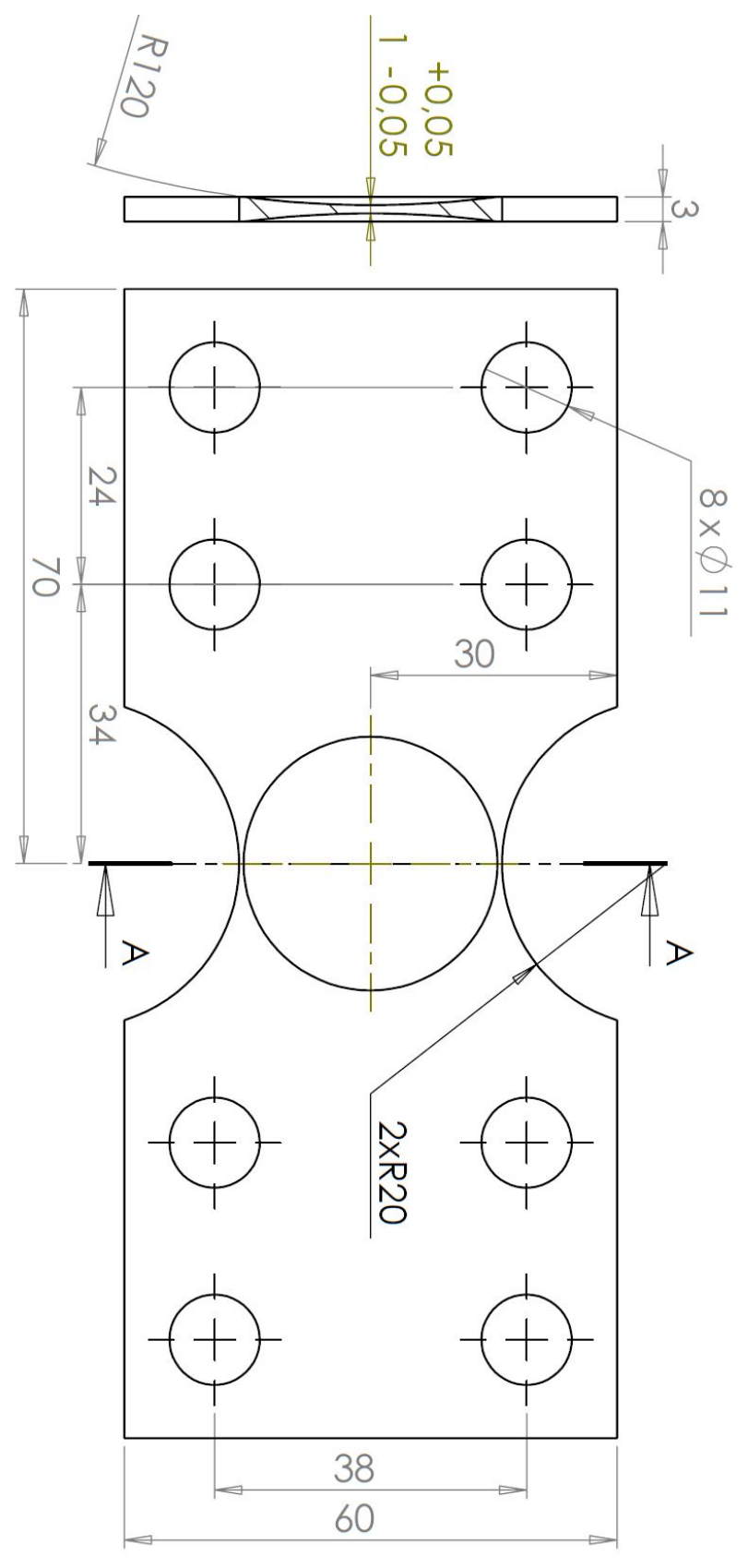

Fig. 5: Shear specimen 


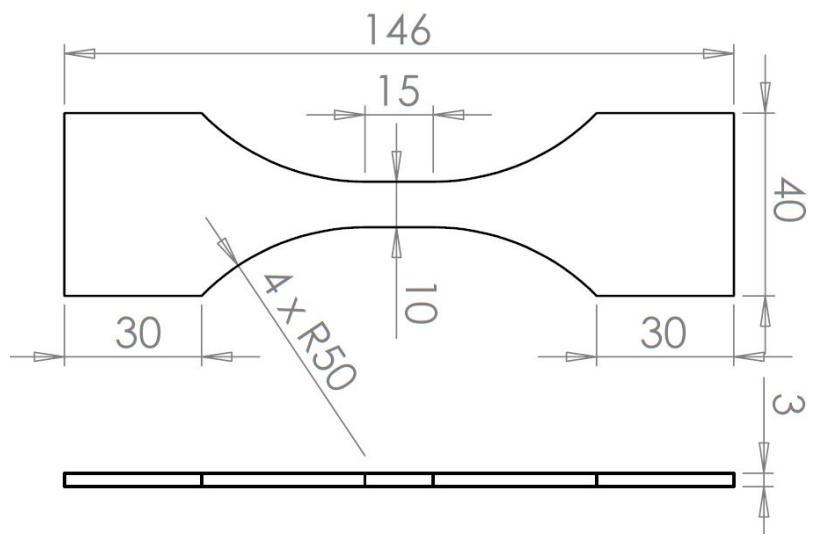

Fig. 6: Tensile specimen

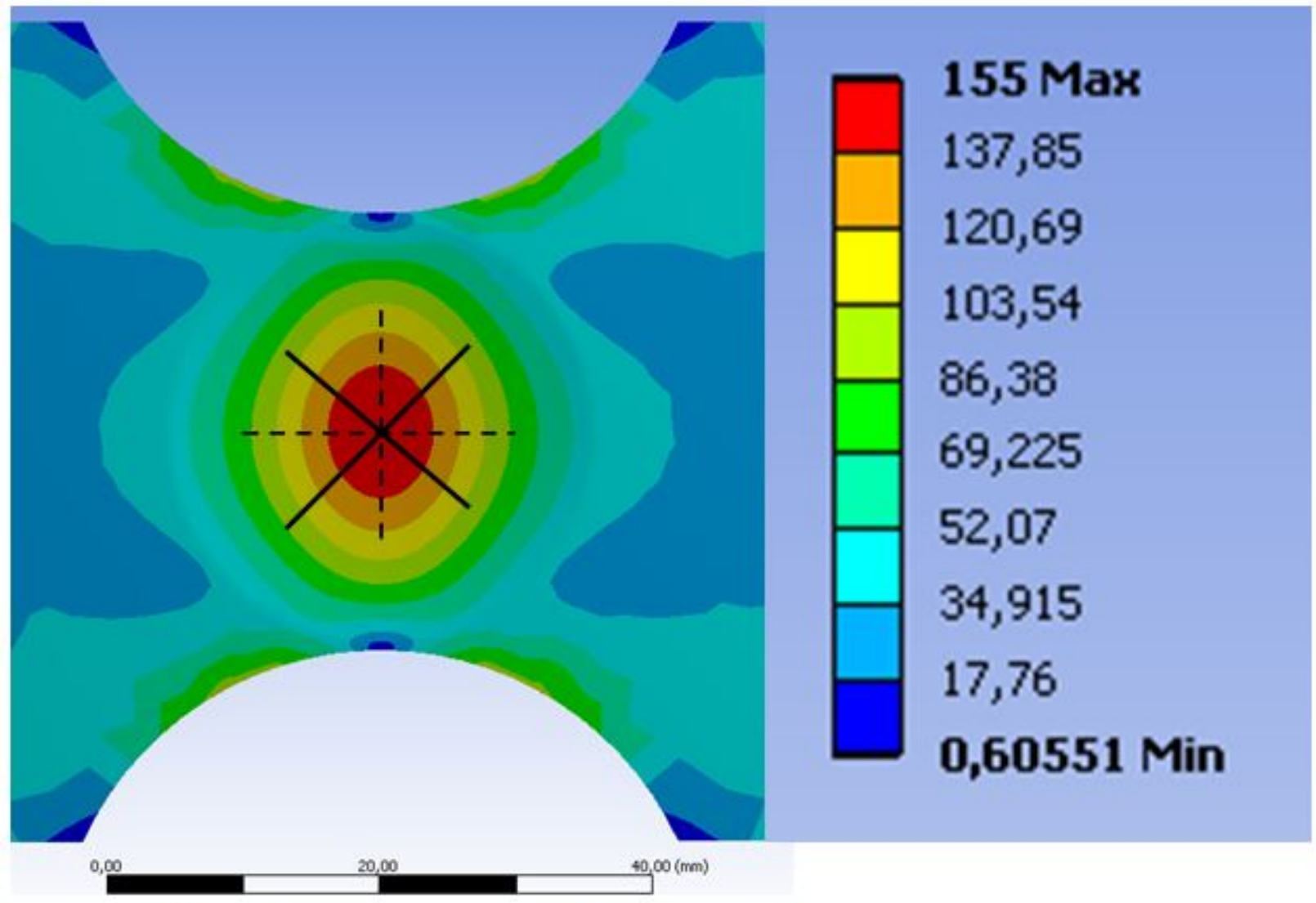

- Maximum normal-stress planes

--- Maximum shear-stress planes

Fig. 7: Von Mises stress from an elastic finite element simulation (MPa) 


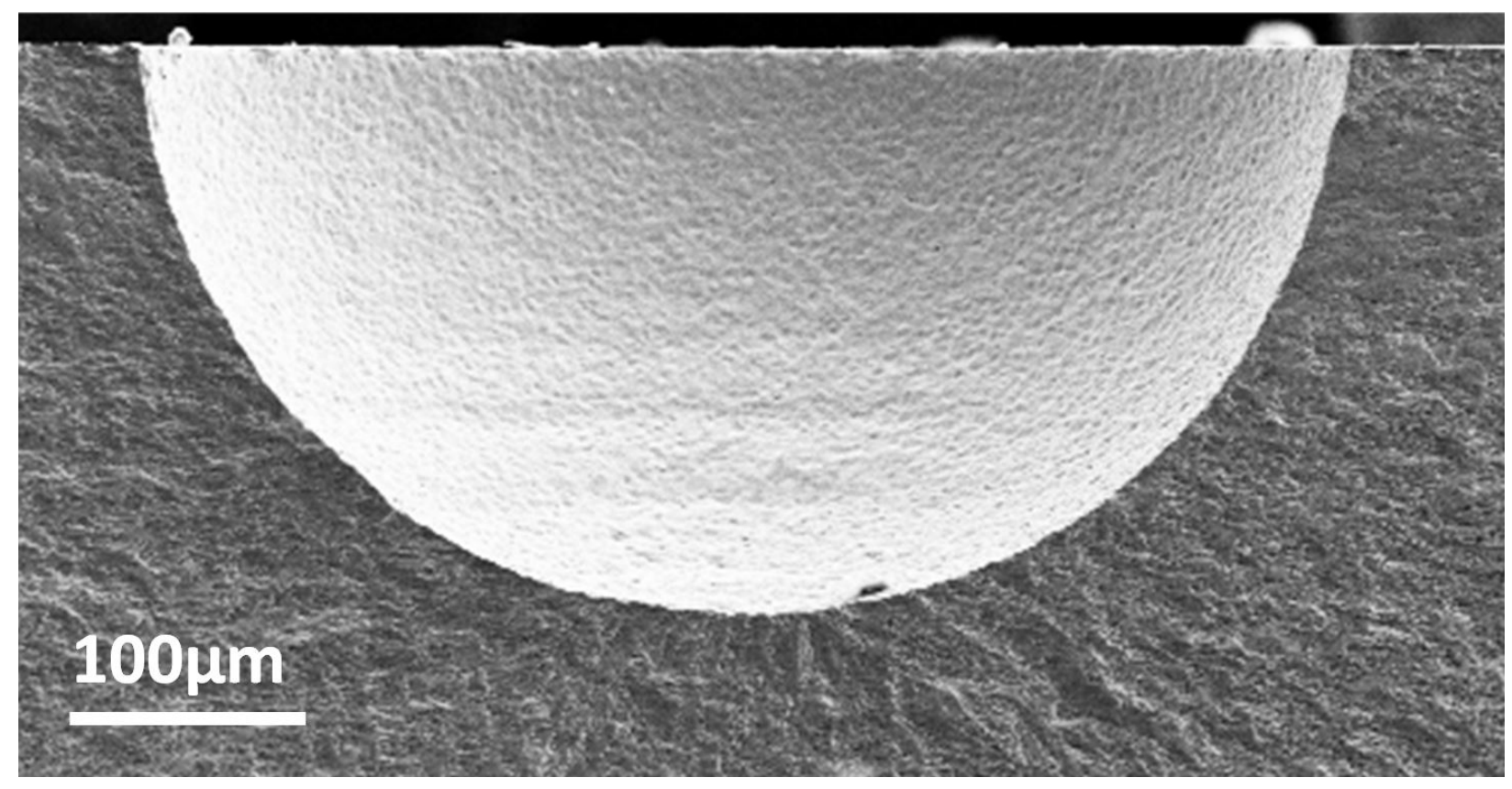

Fig. 8: SEM observation of fatigue crack initiation sites on tensile specimens at an artificial defect $\varnothing 500 \mu m$ 

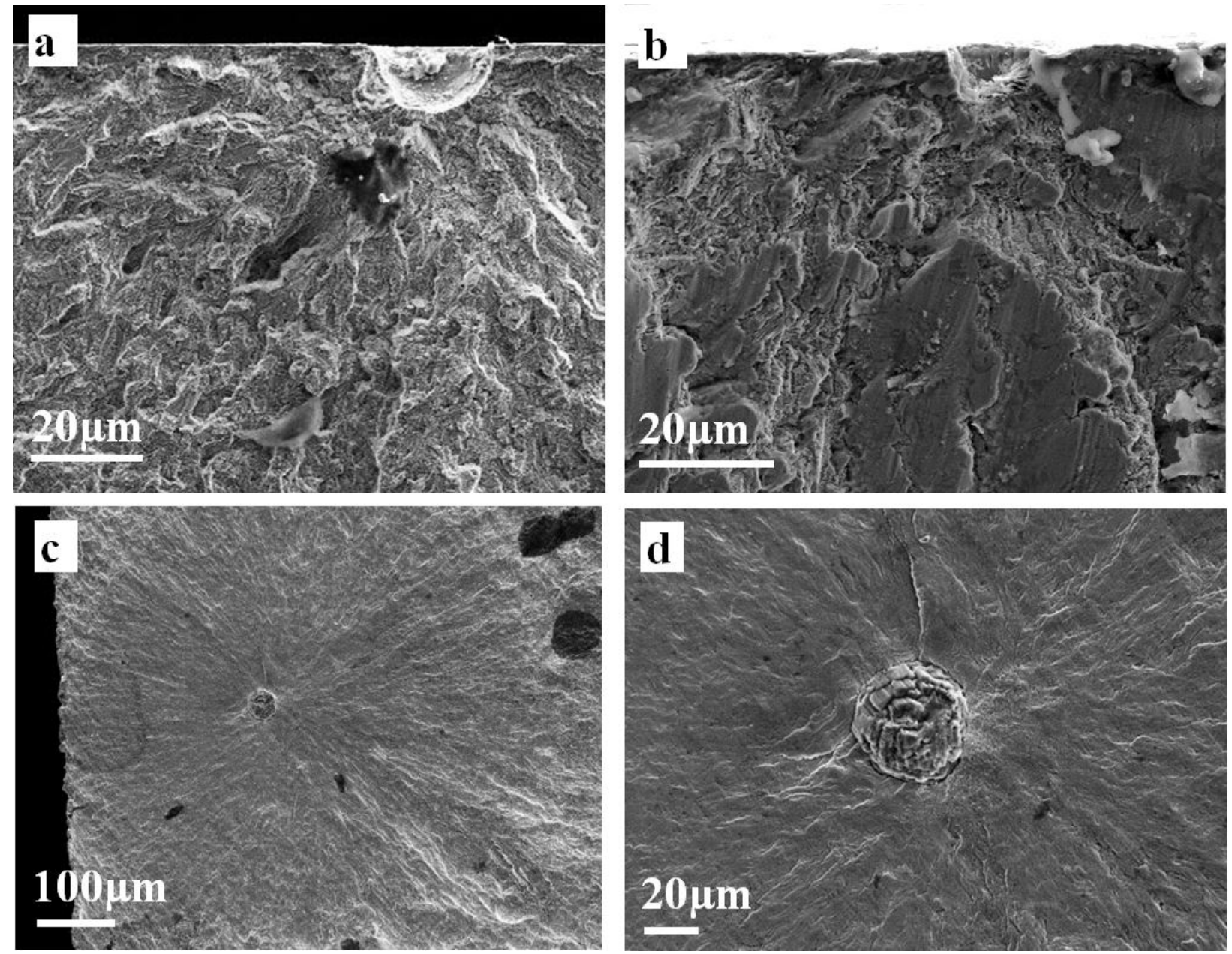

Fig. 9: Crack initiation sites a-b) untreated material, c-d) quenched material showing "Fish eye" fracture surfaces 

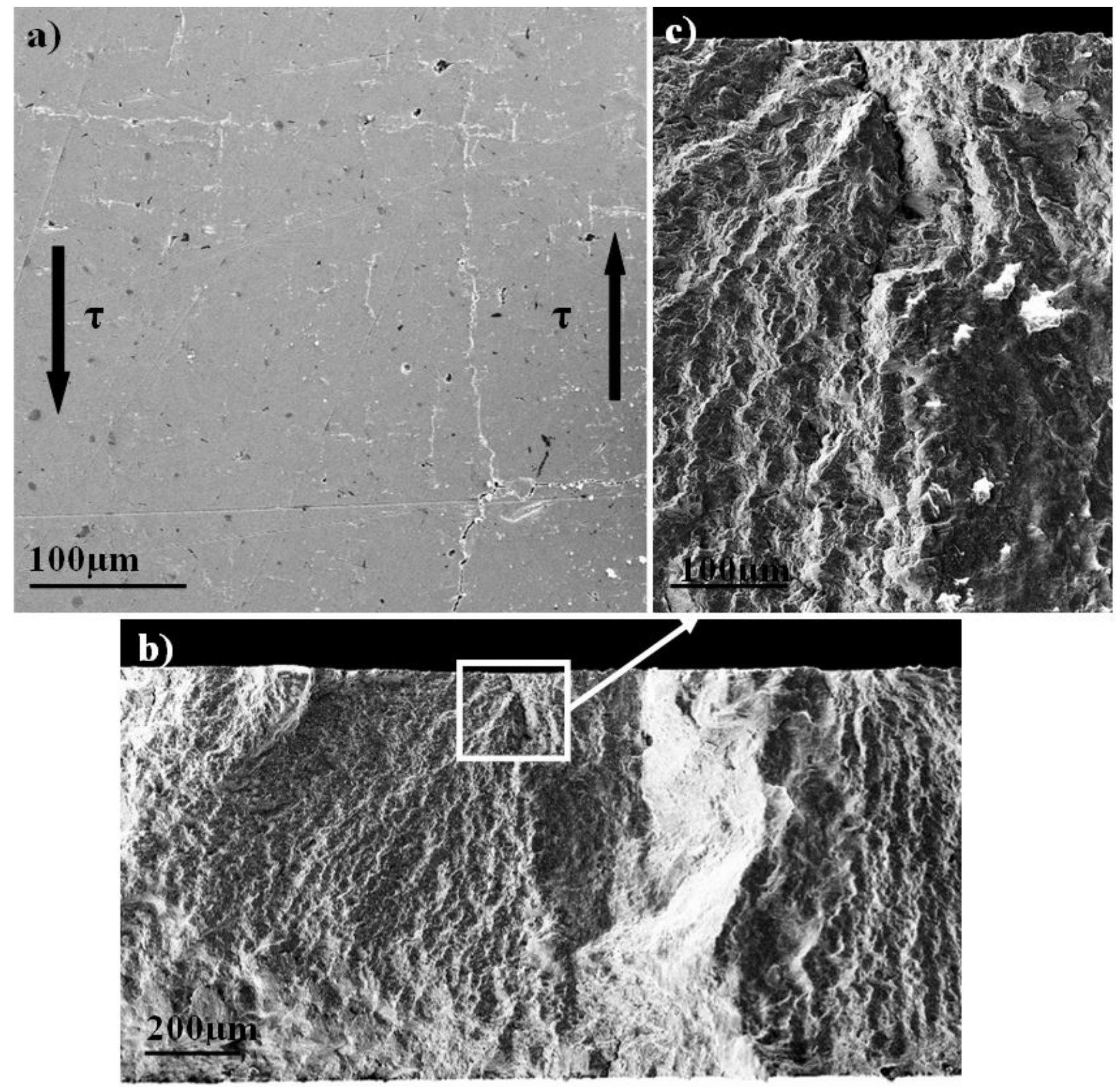

Fig. 10: a) Observation on the surface of a shear specimen showing crack initiation in the material matrix on planes at $0^{\circ}$ and $90^{\circ}$ to the specimen axis, b-c) failure surface for a shear test 

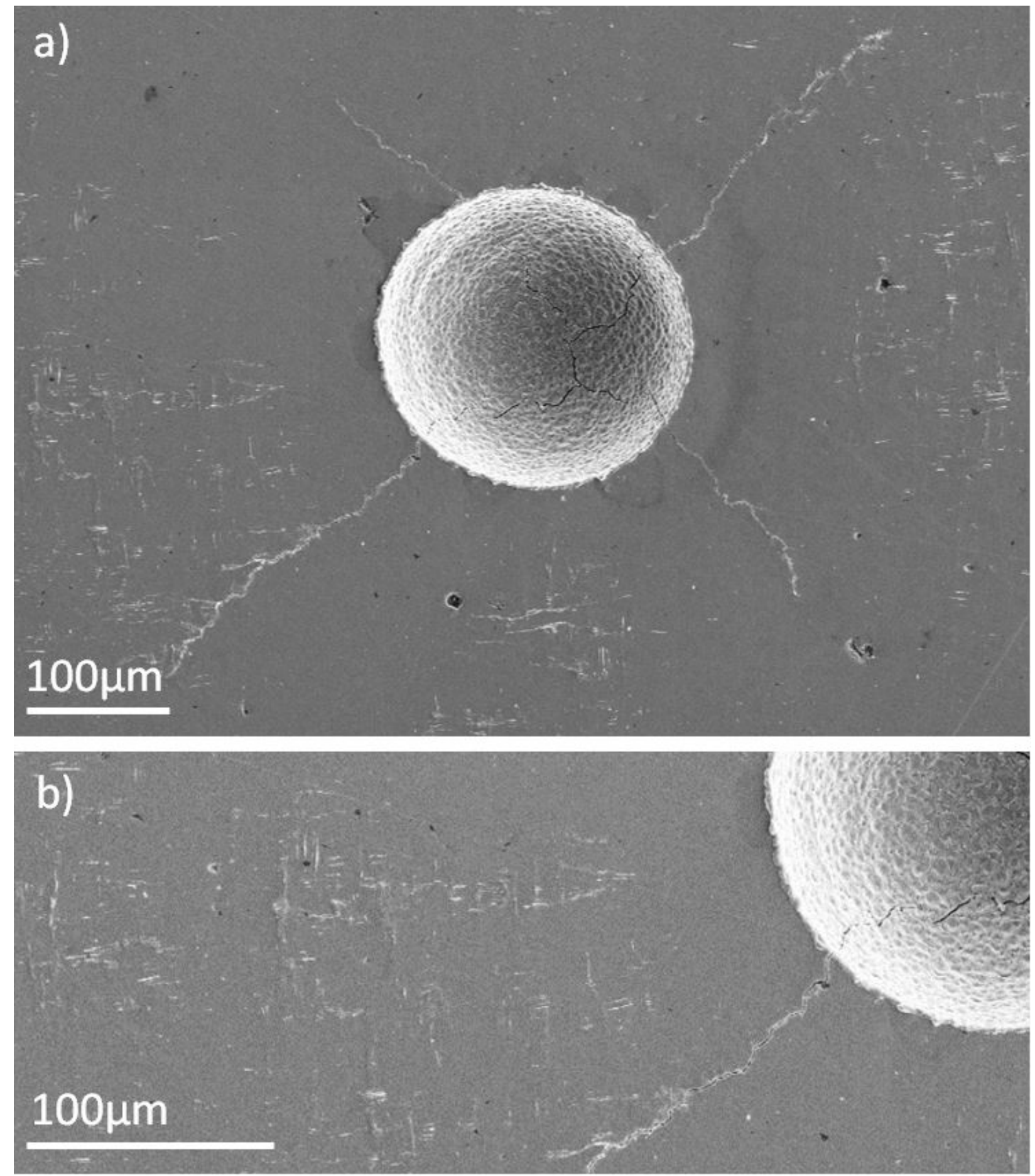

Fig. 11: Surface observations of a shear specimen showing two co-existing fatigue damage mechanisms (a) cracks initiation at the defect $(\varnothing 200 \mu \mathrm{m})$ and propagating on planes of maximum normal stress and (b) cracks initiating in the material matrix on slip planes at $0^{\circ}$ and $90^{\circ}$ to the specimen axis 


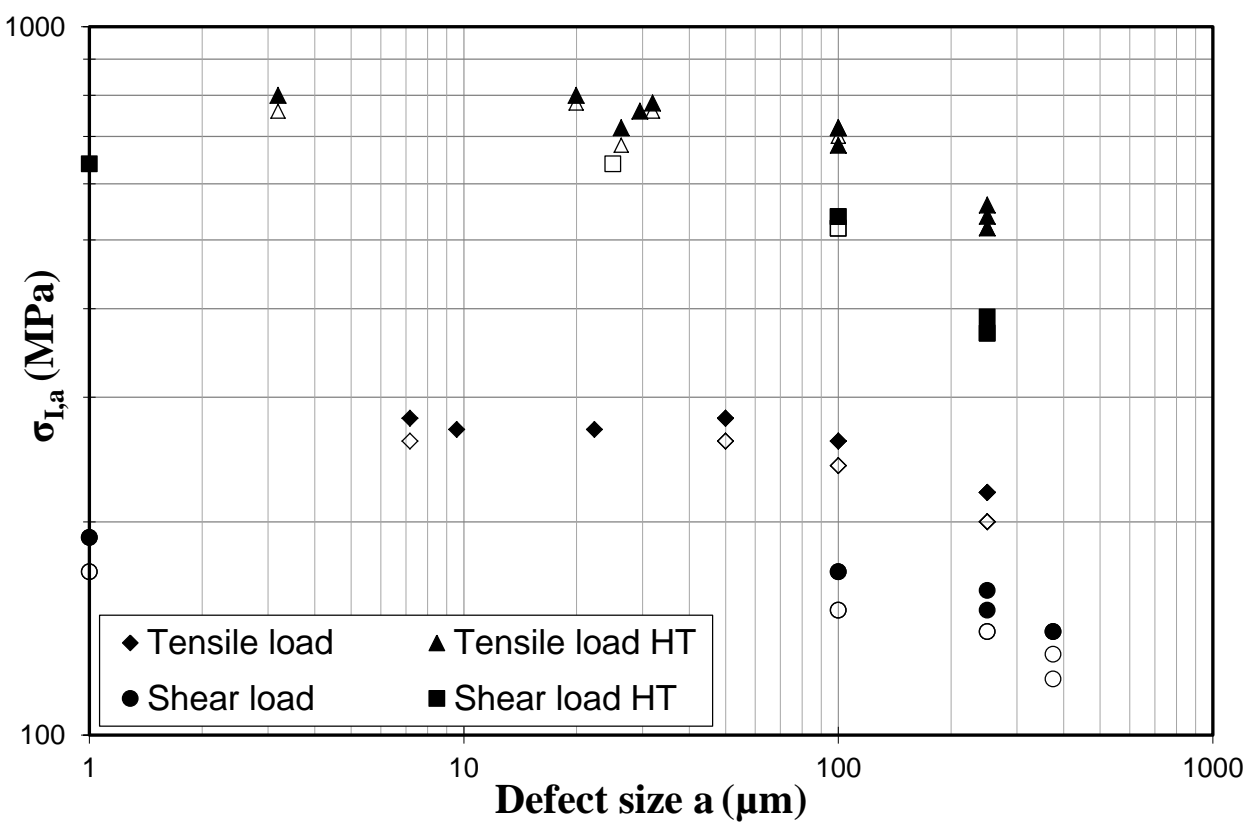

Fig. 12: Kitagawa diagram for the 22MnB5 steel in its initial untreated state and after a quench Heat Treatment (HT) for tensile and shear loads. Defects with a size of less than $50 \mu \mathrm{m}$ are natural defects, unfilled symbol are used for unfailed specimens and filled symbol are used for failed specimens 


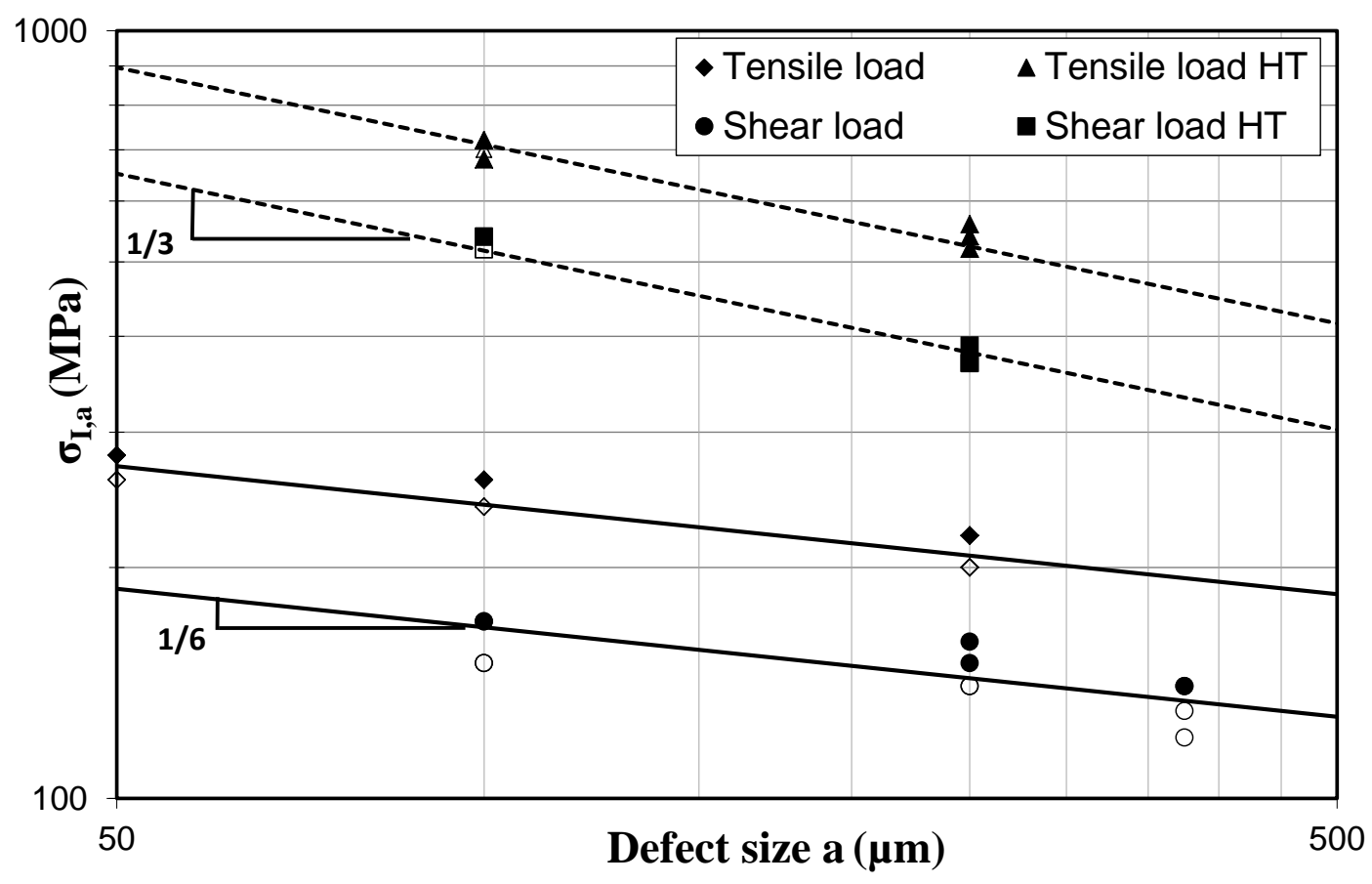

Fig. 13: Kitagawa diagram for the 22MnB5 steel for a defect size range of 100 to $300 \mu m$, HT $=$ Heat Treated or quenched material 


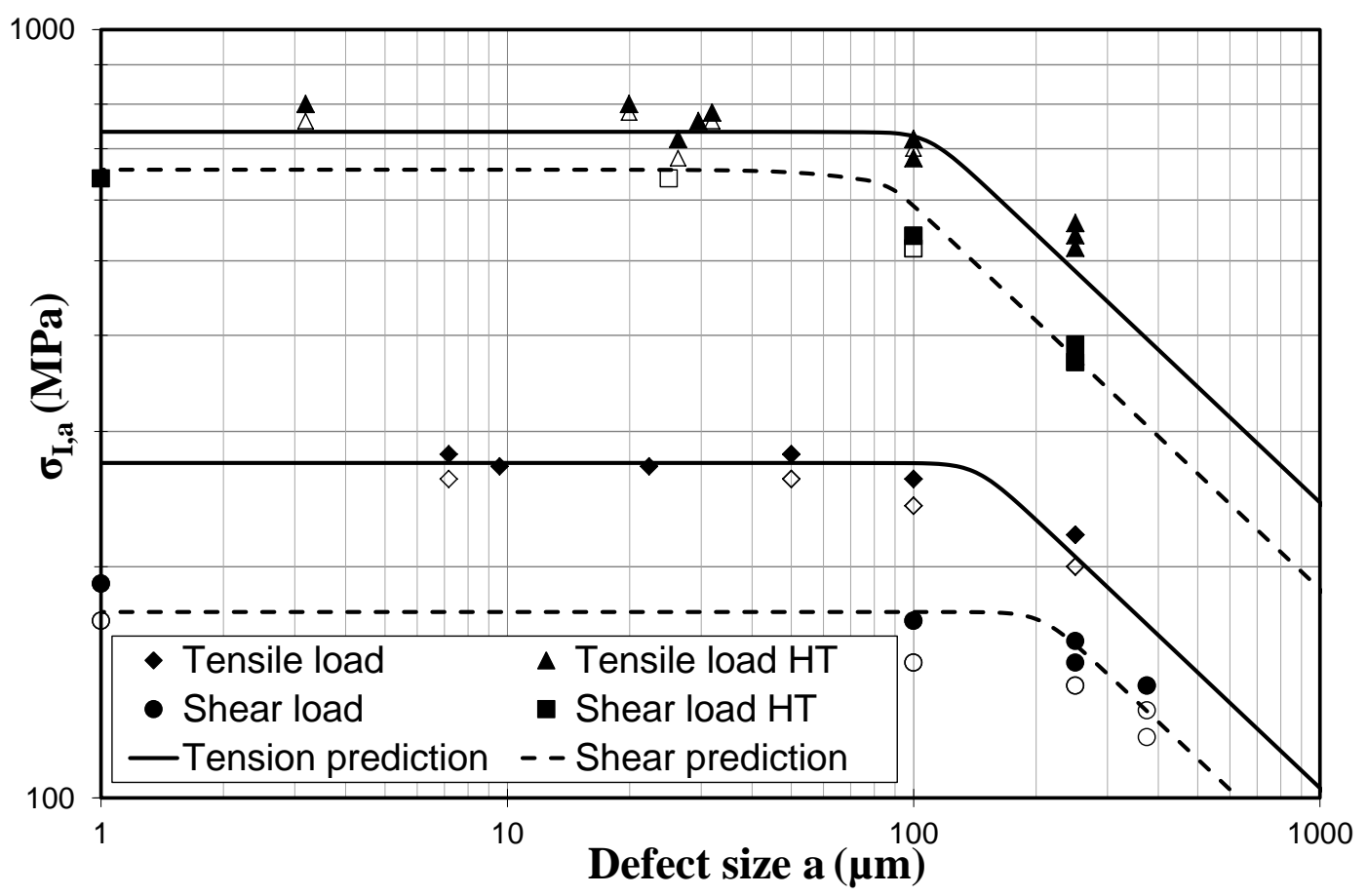

Fig. 14: Kitagawa diagram for the 22MnB5 steel for different loading types, the prediction are calculated using the Papadopoulos and the LEFM criteria 


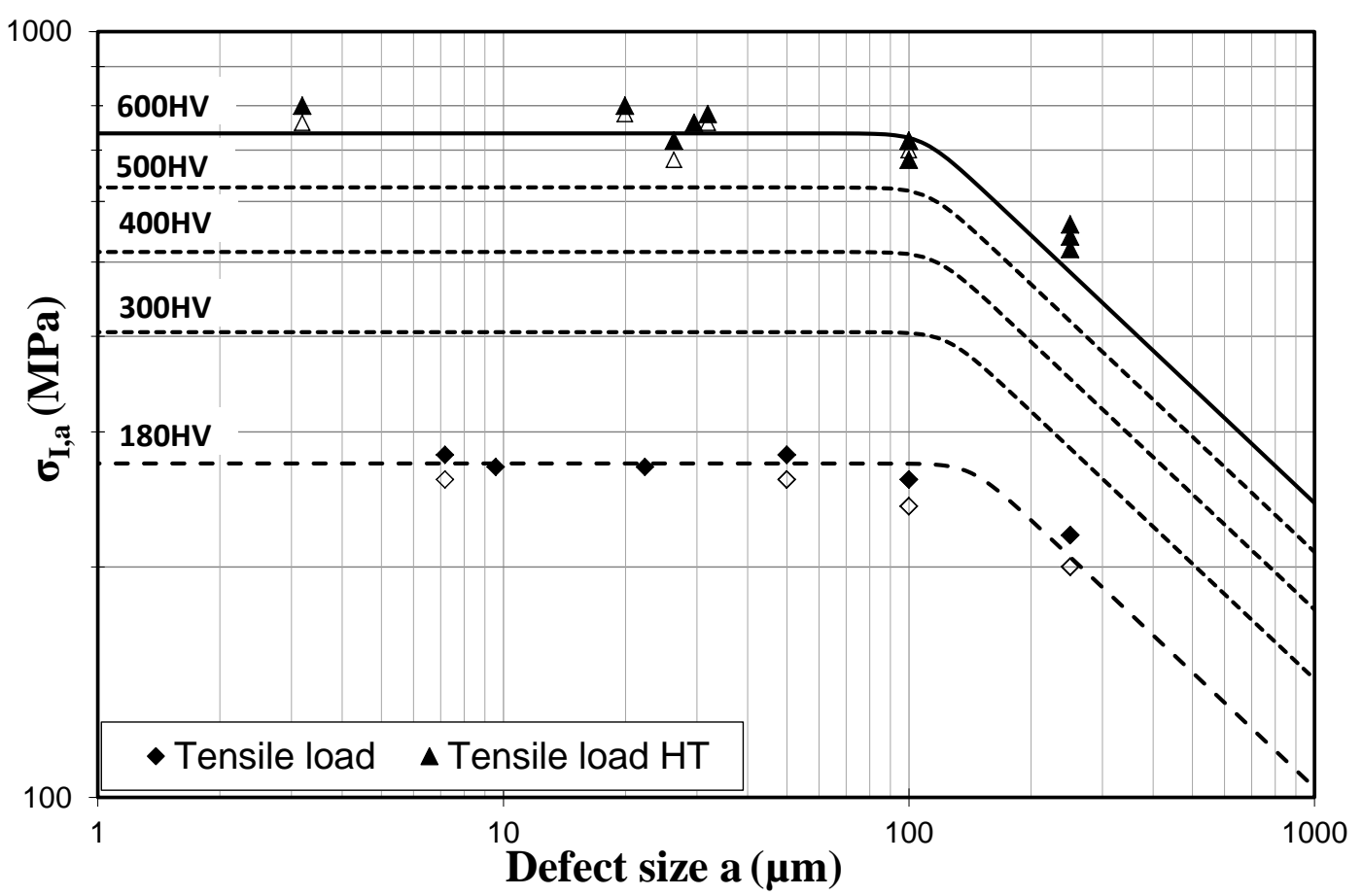

Fig. 15: Kitagawa diagram in tension for the $22 \mathrm{MnB} 5$ steel for different hardness levels, the prediction are calculated using the Papadopoulos and the LEFM criteria 


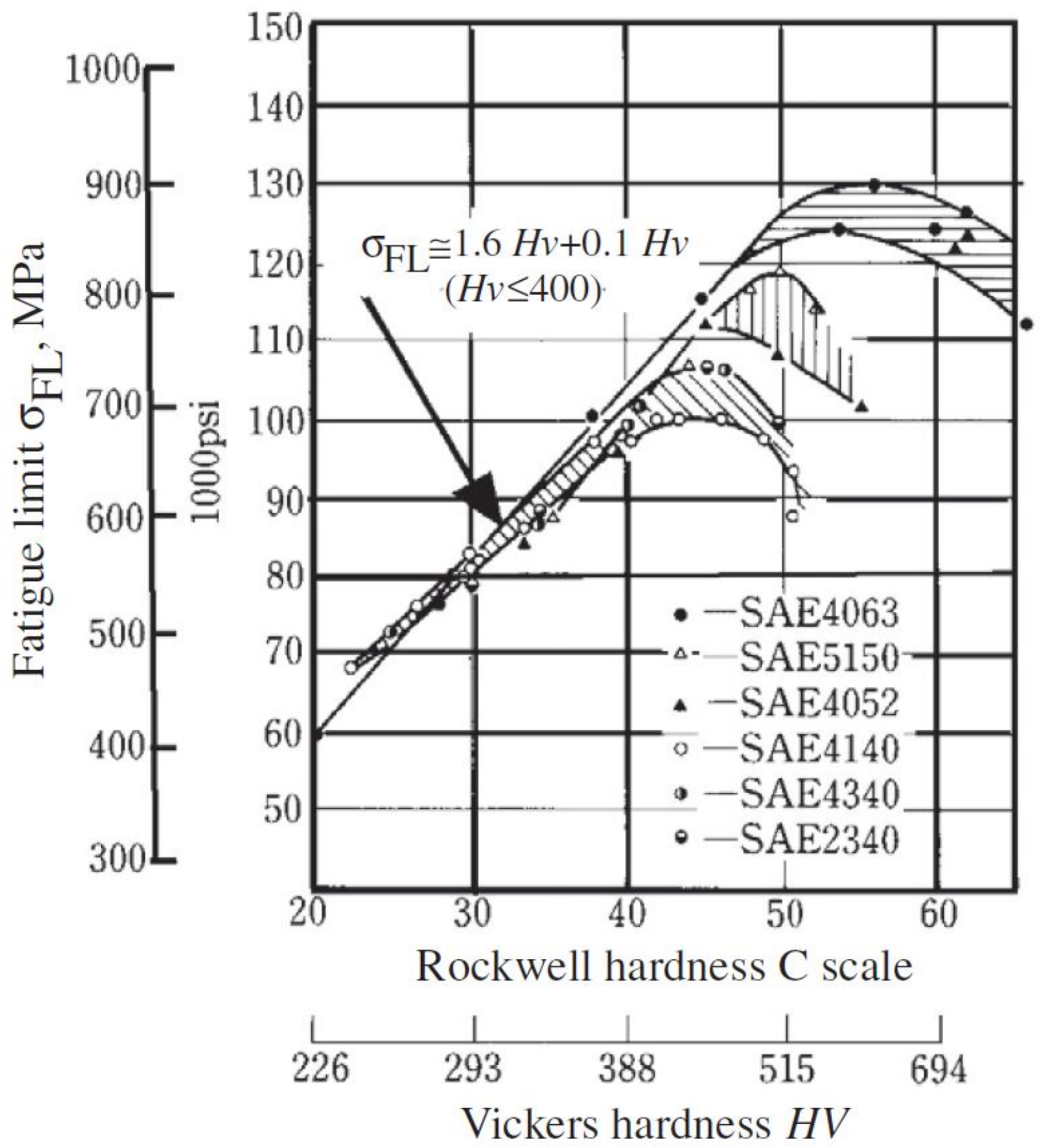

Fig. 16: Relationship between hardness and the fatigue limit (zero mean stress)[Garwood MF, Gensamer M, Zurburg HH, Burwell JT, Erickson MA, La Que FL. Interpretation of Tests and Correlation with Service, American Society for Metals, 1951] 


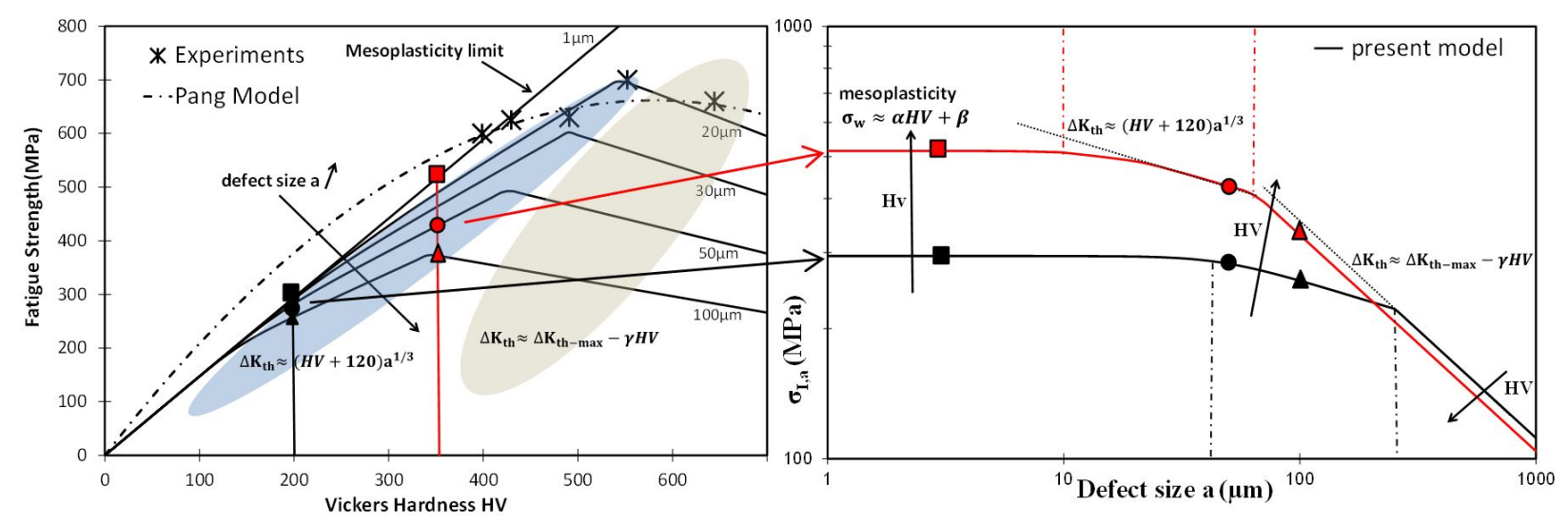

Fig. 17: Fatigue strength prediction in tension versus Vickers Hardness for different defect sizes, for the SAE 4340 steel

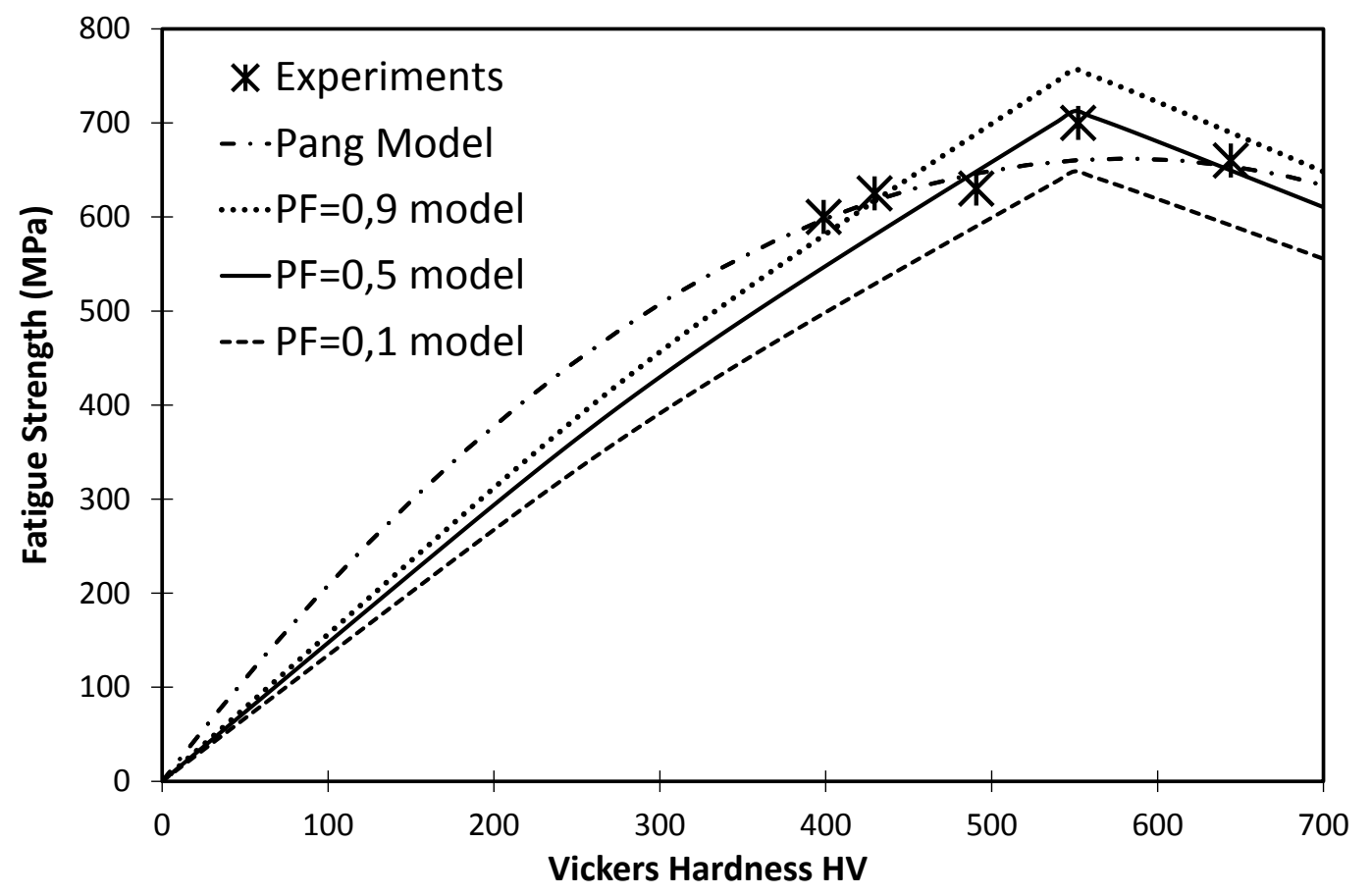

Fig. 18: Fatigue strength prediction in tension versus Vickers Hardness for different failure probabilities, a defect size of $20 \mu m$, for the SAE 4340 steel 